\title{
Le gisement paléolithique de Valle Giumentina (Apennin central) et ses problèmes
}

\author{
Par Jean Demangeot, Toulouse, et A. Mario Radmilli, Pise
}

Avec 19 figures et 2 tableaux

Ré s u mé. La coupe du gisement de Valle Giumentina (situé dans les Abruzzes, vers $700 \mathrm{~m}$ d'altitude) mesure plus de $60 \mathrm{~m}$ de hauteur. Elle comporte, de bas en haut:

A) Des blocs torrentiels (couche no 1); des blocs d'éboulement (no 2) contemporains d'une crise tectonique (Villafranchien supérie ur ?); des galets roulés et cimentés (no 3), probablement interglaciaires.

B) Une pierraille de gélivation (no 4 à 7 ) d'âge vraisemblabement $\mathrm{m}$ in délie $\mathrm{n}$ : les cailloux sont aigus et noyés dans un limon nougeâtre, et les minéraux volcaniques que contient cette matrice semblent provenir des éruptions pré-rissiennes du versant tyrrhénien de la péninsule italienne. Cette pierraille est scellée par une cuirasse (no 8) ferrugineuse, manganésifère, et qui a certainement été formée sous climat semi-tropical, comme le feretto inter Mindel-Riss de la plaine du Pô.

C) Un empilement de couches lacustres calcaréo-sableuses, de paléosols argileux et de cailloutis (couches 9 à 43), témoignant d'un froid croissant (période anaglaciaire). La présence in situ d'instruments du Clactonien évolué (couches 20, 24, 30,33, 40 et 42) et de l'Acheuléen supérieur (couche no 37), la présence d' Ursus spelaeus et de Cervus elaphus enfin la nature plus basique des minéraux volcaniques apportés par le vent, tendent à prouver que cet ensemble $\mathrm{C}$ est $\mathrm{r}$ is s i e $\mathrm{n}$.

D) Un manteau limoneux rougeâtre (no 45 et 47), discordant, d'origine éolienne, significatif d'un climat froid et sec, enserrant un cailloutis de solifluxion no 46 , lequel contient un mélange d'industries de plusieur âges. La question se pose de savoir si les instruments Levalloiso-moustériens de ce mélange sont en place ou non. S'ils sont en place, l'ensemble $D$ est encore $r$ is s i e n : c'est l'opinion de A.M.R., fondée sur l'absence de patine, et par comparaison avec le gisement des Svolte, récemment découvert près de Popoli. S'ils ne sont pas en place, l'ensemble D est w ü rmien : c'est l'opinion de J. D., fondée sur l'ensemble du contexte sédimentologique.

Valle Giumentina peut donc être considérée comme l'un des plus intéressants gisements quaternaires à ciel ouvert de l'Italie centrale.

$\mathrm{Z} u s$ a $\mathrm{m}$ e $\mathrm{n} f$ as su $\mathrm{ng}$. Das Profil im Valle Giumentina (Abruzzen, ca. $700 \mathrm{~m}$ ü.N.N.) ist über $60 \mathrm{~m}$ hoch. Es enthält vom Liegenden zum Hangenden:

A.) Wildbach-Blöcke (Schicht Nr. 1); abgerutschte Blöcke, die tektonische Unruhe anzeigen ( $\mathrm{Oberes} \mathrm{Vill}$ af $\mathrm{ranch}$ ie $\mathrm{n}$ ?); abgerollte und miteinander verbackene, wahrscheinlich interglaziale Gerölle.

B.) Frostsprengungs-Schutt (Nr. 4-7), wahrscheinlich von M in d e 1-Alter: die Bestandteile sind eckig und in einen rötlichen Lehm eingebettet; die in der Matrix enthaltenen vulkanischen Mineralien scheinen Prä-Riß-Eruptionen auf der tyrrhenischen Seite der italienischen Halbinsel zu entstammen. Der Schutt ist von einer manganhaltigen Eisenkruste überdeckt (Nr. 8), die sich sicher unter einem semi-tropischen Klima gebildet hat, vergleichbar dem Mindel-Riss- „Feretto“ der Po-Ebene.

C.) Einen Schichtstapel lakustrer kalkig-sandiger Sedimente, toniger Paläoböden und Schotter (Schichten 9-43), der zunehmende Kälte bezeugt (anaglaziale Periode). Artefakte des fortgeschrittenen Clactonien (Schichten 20, 24, 30, 33, 40 und 42) und des oberen Acheuléen (Schicht Nr. 37) in situ, Funde von Ursus spelaeus und von Cervus elaphus und endlich der stärker basische Charakter der vom Wind angewehten vulkanischen Gemengteile lassen die Annahme zu, daß die Schichtengruppe $C$ dem $R$ i $\beta$ angehört.

D.) Rötliche lehmige Deckschichten, diskordant auf C, äolischen Ursprungs, auf ein kaltes und trockenes Klima hinweisend, enthalten einen Solifluktionsschutt (Nr. 46), der ein Gemenge verschieden alter Artefakte enthält. Es stellt sich die Frage, ob dabei die Levallois-MoustérienArtefakte autochthon sind oder nicht. Wenn sie autochthon sind, dann gehört die Schichtgruppe D noch dem $\mathrm{R}$ i $\beta$ an: das ist die Ansicht von A.M.R., die sich auf das Fehlen einer Patina und den Vergleich mit dem erst kürzlich entdeckten, nahe Popoli gelegenem Vorkommen von Svolte gründet. Wenn sie allochthon sind, dann gehört die Schichtgruppe D dem W ü rm an: das ist die Auffassung von J. D., die sich auf sedimentologische Kriterien stützt.

Valle Giumentina kann damit als eines der interessantesten quartären Vorkommen in Mittelitalien angesehen werden. 
La première information sur l'existence d'industrie lithique à Valle Giumentina remonte au début du siècle et elle dûe à C. Bianchini (C. Rosa in Balzano 1909). G. Bonarelli eut ensuite l'occasion de visiter les lieux et d'en parler incidement à C. Maviglia. Ce n'est qu'en 1952 que le gisement fut retrouvé, par A. M. Radmilli, et que son importance exceptionnelle fut reconnue (Radmilli 1953). A. M. Radmilli en entreprit alors l'étude en collaboration avec J. DEMANGEOT pour la partie sédimentologique (Demangeot \& Radmilli 1953a et b, Leonardi \& Radmilli 1956). C'est le résultat des fouilles systématiques de 1954-1955 et des études de laboratoire qui ont suivi, qui est exposé ici.

Le lieu dit "Valle Giumentin a" se trouve en Italie centrale, dans la province de Chieti, au pied septentrional de la Majella, vers $700 \mathrm{~m}$ d'altitude. Le site consiste en un alvéole lacustre actuellement desséché et mis en culture. Grâce à l'entaille récente d'un petit ravin on peut observer dans le remblaiement alluvial, et de bas en haut, la succession stratigraphique suivante (fig. 1 ):

- couches 1 à 3: $25 \mathrm{~m}$ de cailloux et de blocs partiellement torrentiels et d'âge incertain (e n s e m b l e A);

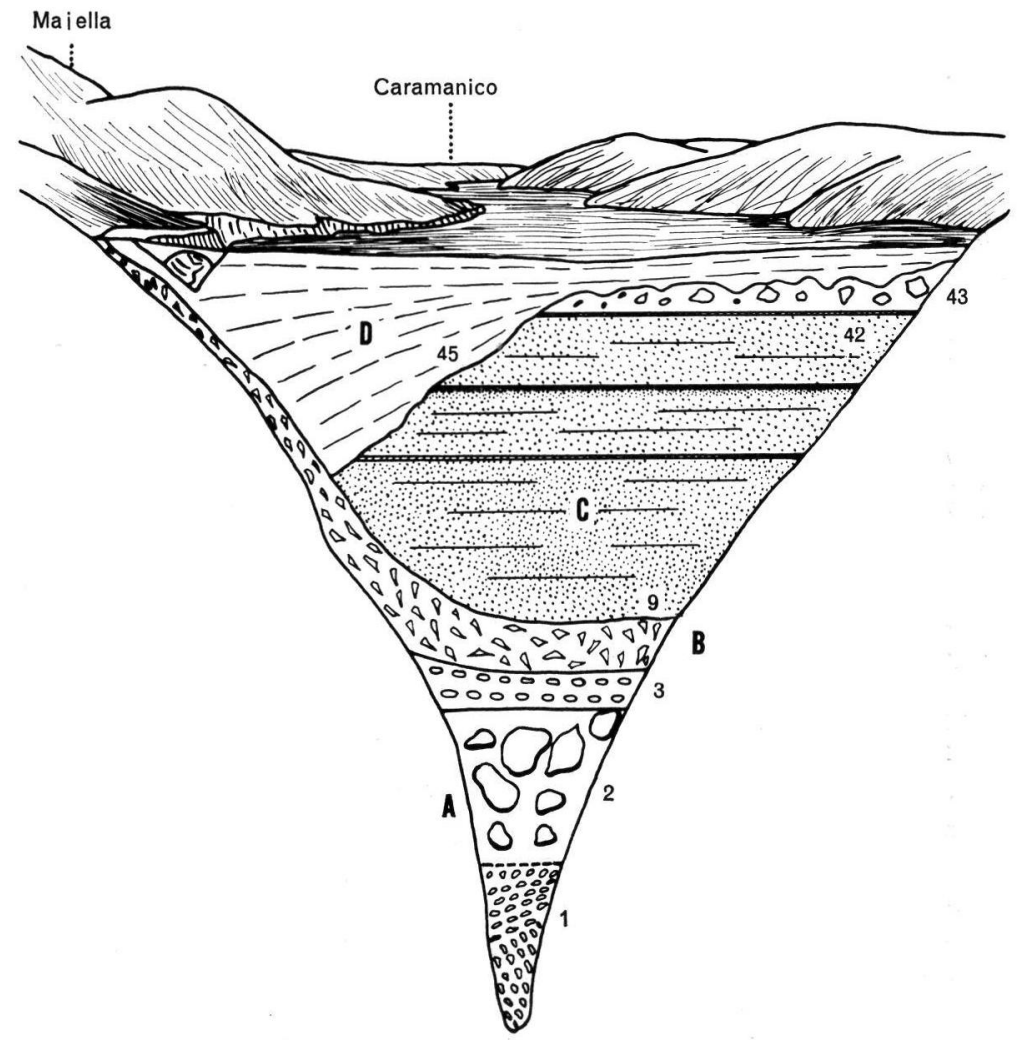

Fig. 1. Coupe générale du gisement de Valle Giumentina. La Majella serait à gauche du croquis. Pour plus de clarté l'épaisseur des couches a été exagérée. On voit de bas en haut le complexe de cailloux et de blocs pré-mindéliens $A$; les brèches périglaciaires mindéliennes $B$, surmontées par la croûte ferrugineuse no. 8; les dépôts lacustres rissiens $\mathrm{C}$ à industrie clactonienne et acheuléenne; le remplissage terreux würmien $\mathrm{D}$ à Paléolithique supérieur. Noter les trois discordances. 
- couches 4 à $8: 4$ à $10 \mathrm{~m}$ de brèches périglaciaires rougeâtres d'âge probablement mindélien (e n s e m b l e B);

- couches 9 à 43: $25 \mathrm{~m}$ de dépôts lacustres variés, que la présence de Cervus elaphus et d'une abondante industrie clactonienne et acheuléenne en place fait remonter au Rissien (e n s e m b l e C);

- couches 45 à 48: 1 à $4 \mathrm{~m}$ d'un remplissage discordant terreux rougeâtre daté du Würmien par de l'industrie du Paléolithique supérieur (e n s e m b le D).

$\mathrm{La}$ datation générale de ces couches pouvant être considérée comme acquise (seules les couches 45 et 46 font encore discussion), nous pensons que l'étude typologique doit précéder l'étude sédimentologique.

18

\section{Première partie: Palethnologie du gisement ${ }^{1}$ )}

I. Description sommaire des couches (voir Seconde partie, et figures 1 et 16).

II. L'industrie lithique

Pour la fabrication des instruments ont été utilisés des éclats de silex ou des rognons, et, plus rarement, des cailloux alluviaux siliceux. Dans la couche 20 on trouve des pièces en silex aux multiples nuances de marron, tandis que dans les couches 30,33,40,42, elles sont d'un gris bleuâtre plus ou moins altéré. Les pièces de la couche 37 sont en silex gris clair ou blanc jaunâtre; quelques objets sont d'une couleur blanchâtre très altérée. Mais plusieurs qualités de silex ont été employées pour les instruments de la couche 46.

Il ressort de ce qui précède que les hommes dont la couche 20 nous fournit les traces prélevaient leurs matières premières dans un lieu différent de celui choisi par les hommes des couches $30,33,40$ et 42 , et les gisements des silex exploités par les populations de la couche 37 diffèrent également des précédents.

$\begin{array}{llr}\text { Couche 20 } & \text { (à droite, nombre de pièces récoltées) } \\ \text { (figure 2) } & \text { débris } & 38 \\ & \text { éclats atypiques } & 57 \\ & \text { nucleus } & 1 \\ & \text { percuteurs } & 3 \\ & \text { racloirs } & 7\end{array}$

L'un des éclats appartenant aux débris présente une patine très archaïque, tandis qu'un autre montre une double patine. Huit exemplaires d'éclats atypiques portent des ébréchures dûes à l'usure: ils ont tous le talon, c'est à dire le plan de percussion, incliné par rapport à la face d'éclatement. En outre ce talon se développe plus dans le sens transversal qu'en profondeur, de telle sorte qu'il reste étroit, ce qui révèle le débitage par emploi d'un percuteur.

Les nucleus ont une forme polyédrique plus ou moins régulière. Un gros éclat présentant sur l'arête opposée au talon des ébréchures, a probablement été utilisé comme percuteur ou comme retoucheur. Les racloirs sont du type latéral. Les éclats avec encoches sont typiquement clactoniens. Quant aux instruments à becs ils se composent de gros éclats et de quelques nucleus: ces derniers présentent sur les arêtes un ou plusieurs becs dont l'axe coïncide avec la ligne de confluence de deux éclats détachés latéralement au bec. Ces becs peuvent également avoir deux encoches.

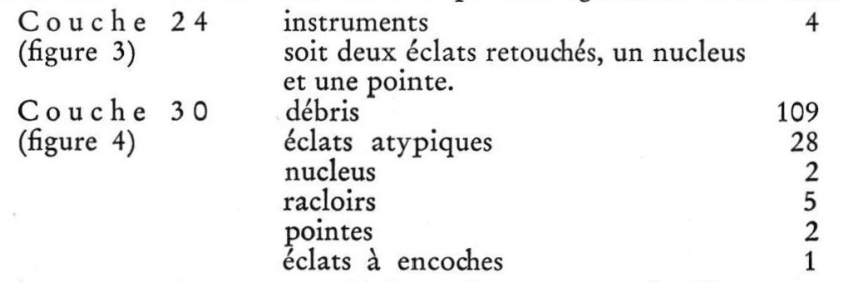

L'un des nucleus a une forme pyramidale et l'autre est irrégulièrement polyèdrique. Les racloirs ont le talon lisse et incliné: l'un est transversal à bord droit et retouche imbriquée, un

1) Par A. M. Radmilli, Professeur à l'Institut d'Anthropologie et de Paléontologie Humaine de l’Université de Pise, Italie. 
autre, du type latéral, a sa marge convexe, et les deux autres ont été retouchés sur les faces adjacentes, faces à profil convexe. Les deux pointes provenant d'éclats à section triangulaire présentent une retouche imbriquée.

Couche 33
(figure 5 )

$\begin{array}{lr}\text { débris } & 142 \\ \text { éclats atypiques } & 183 \\ \text { nucleus } & 3 \\ \text { racloirs } & 40 \\ \text { grattoirs } & 1 \\ \text { pointes } & 2 \\ \text { instrument à encoches } & 4 \\ \text { instruments à becs } & 8\end{array}$

La plupart des nucleus ont une forme irrégulièrement polyédrique et quelques exemplaires sont du type pyramidal tronqué. Pour les racloirs le talon est lisse, étroit et incliné; la retouche, imbriquée ou quasi imbriquée, est abrupte pour les racloirs sur gros éclats, tandis qu'elle envahissante pour ceux obtenus d'éclats plus minces ou à bord mince. Il y a 28 racloirs latéraux, 4 doubles et 8 transversaux. Le grattoir a été tiré d'un éclat à section triangulaire. Les deux pointes présentent une retouche imbriquée; la base de l'une d'elles a été amincie par l'enlèvement d'un éclat sur la face opposée au plan de frappe et par retouche.

$\begin{array}{llr}\text { Couche } 37 & \text { débris } & 475 \\ \text { (figure 6) } & \text { éclats atypiques } & 11 \\ & \text { bifaces } & 5 \\ & \text { racloirs } & 3 \\ & \text { pointes } & 6\end{array}$

A la préparation des bifaces correspondent la plupart des petits éclats minces et lamellaires qui représentent la majeure partie des débris. En effet, dans tous les exemplaires amygdaloïdes, la préparation du biface donne des éclats minces. Une ébauche d'amygdale présente un mode d'enlèvement par larges et profonds éclats alternés, mode qui confère une allure très sinueuse aux arêtes. Les racloirs sont du type transversal à bord plus ou moins convexe, avec talon lisse et incliné et retouche imbriquée ou envahissante. Les pointes sont atypiques car elles ne sont pas retouchées sur les deux bords, vers l'extrêmité.

$\begin{array}{llr}\text { Couche } 40 & \text { débris } & 24 \\ \text { (figure 7) } & \text { éclats atypiques } & 18 \\ & \text { nucleus } & 2 \\ & \text { percuteurs } & 1 \\ & \text { racloirs } & 2\end{array}$

Le percuteur est très semblable à celui de la couche 20 . Les racloirs sont représentés par le type transversal et le type latéral. Parmi les éclats à encoches, l'un présente un bord avec retouche denticulée inverse.

$\begin{array}{lll}\text { Couche } 42 & \text { débris } & 2 \\ & \text { éclats atypiques } & 7 \\ & \text { nucleus } & 2 \\ & \text { racloirs } & 6\end{array}$

Les racloirs sont du type latéral, ils ont une arête convexe et un talon lisse et incliné. Un éclat présente, en plus des encoches, une retouche irrégulière denticulée.

$\begin{array}{llr}\text { Couche } 45 & \text { débris } & 20 \\ & \text { éclats atypiques et lames } & 10 \\ & \text { racloirs } & 2 \\ & \text { instruments à becs }\end{array}$

Ces pièces ont été découvertes dans la partie supérieure de la couche, et il n'est pas exclu qu'elles puissent provenir de la couche supérieure

$$
\begin{array}{llr}
\text { Couche } 46 & \text { débris } & 1570 \\
& \text { instruments } & 544
\end{array}
$$

Dans cette couche très riche la plupart des objets sont en gisement secondaire par suite de l'action de la solifluction qui les a mis en place. Il s'agit d'une industrie culturellement hétérogène, et la matière première employée et les patines sont également variables, selon que les pièces sont anciennes ou récentes. En prenant une vue d'ensemble de tout cet outillage, on trouve d'une part des industries sur éclats, d'autre part des outils préparés avec la retouche biface. 

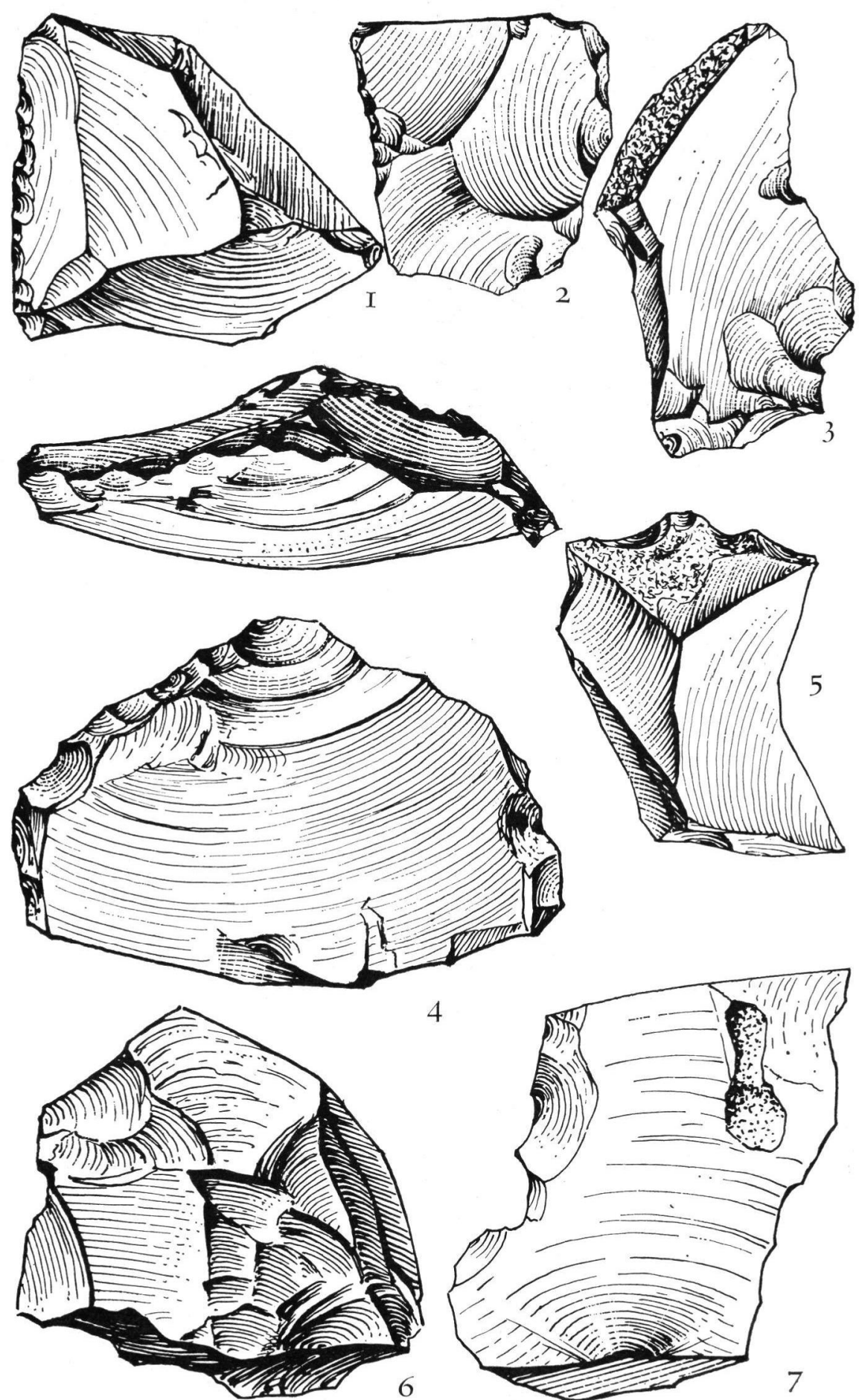

4

6

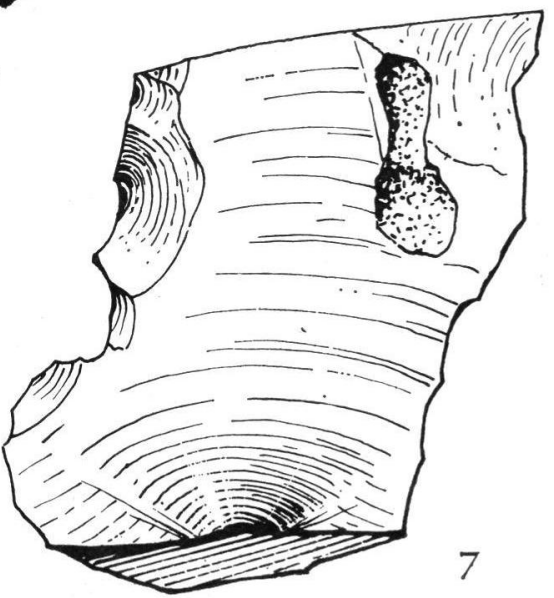

Fig. 2. Industrie de la couche 20. 1 et 2, racloirs; 3 et 7, lames à encoches clactoniennes; 4, percuteur; 5, instrument à bec; 6 , nucleus. Tous les dessins, de la figure 2 à la figure 10, sont environ grandeur naturelle. $(\times 0.95)$. 

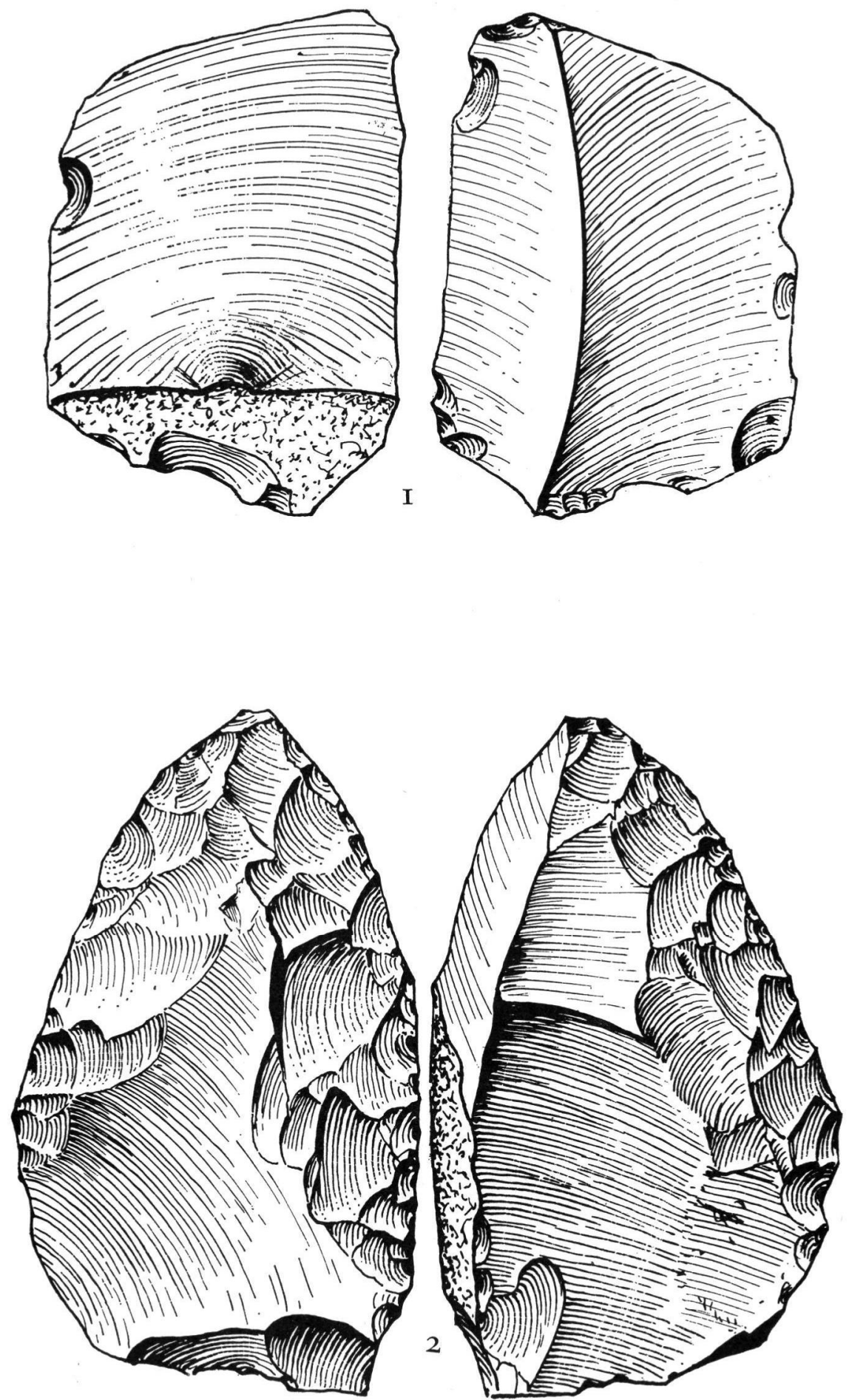

Fig. 3. Industrie. 1, éclat écaillé prélevé entre les couches 24 et $30 ; 2$, pointe de la couche 24. 

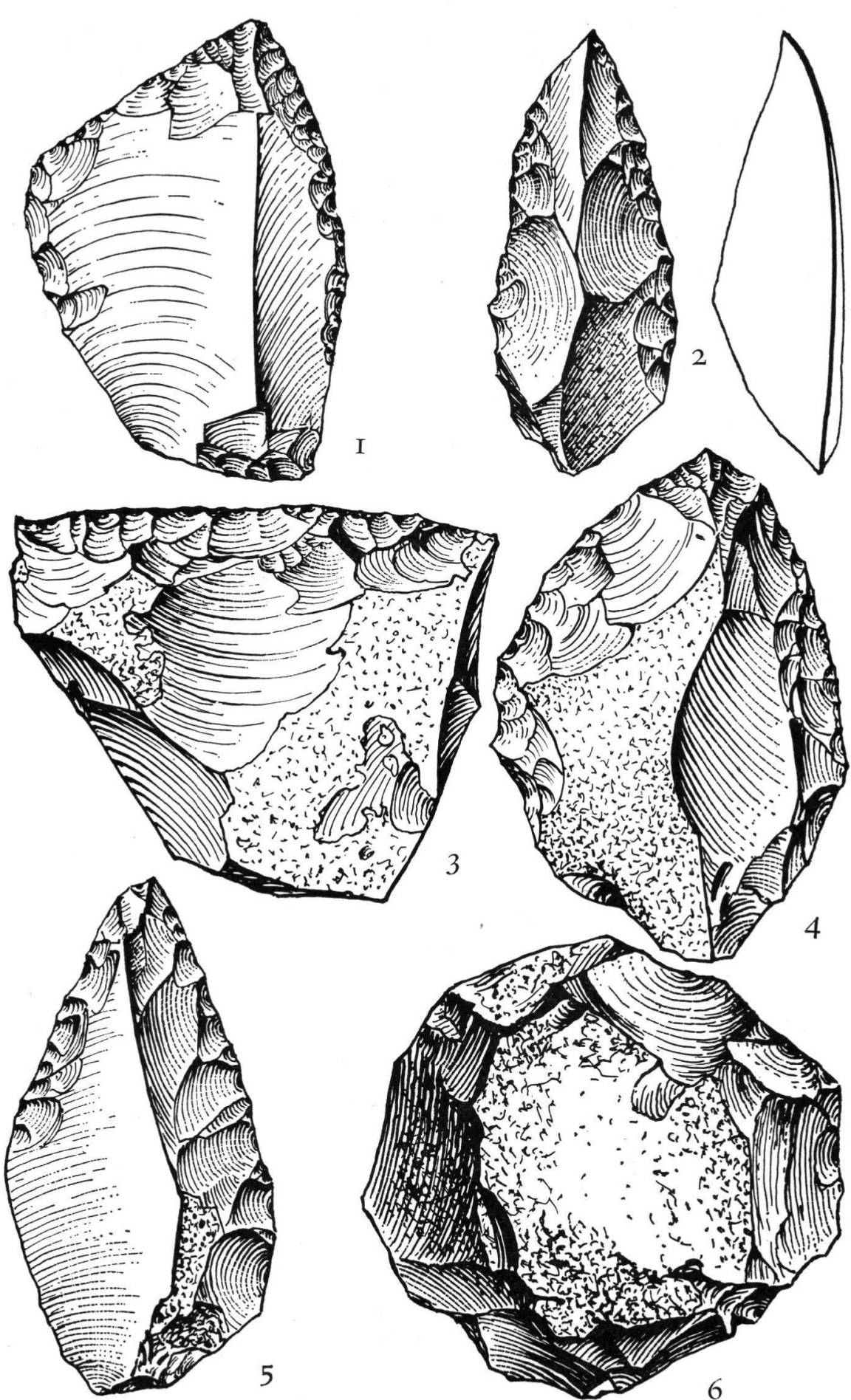

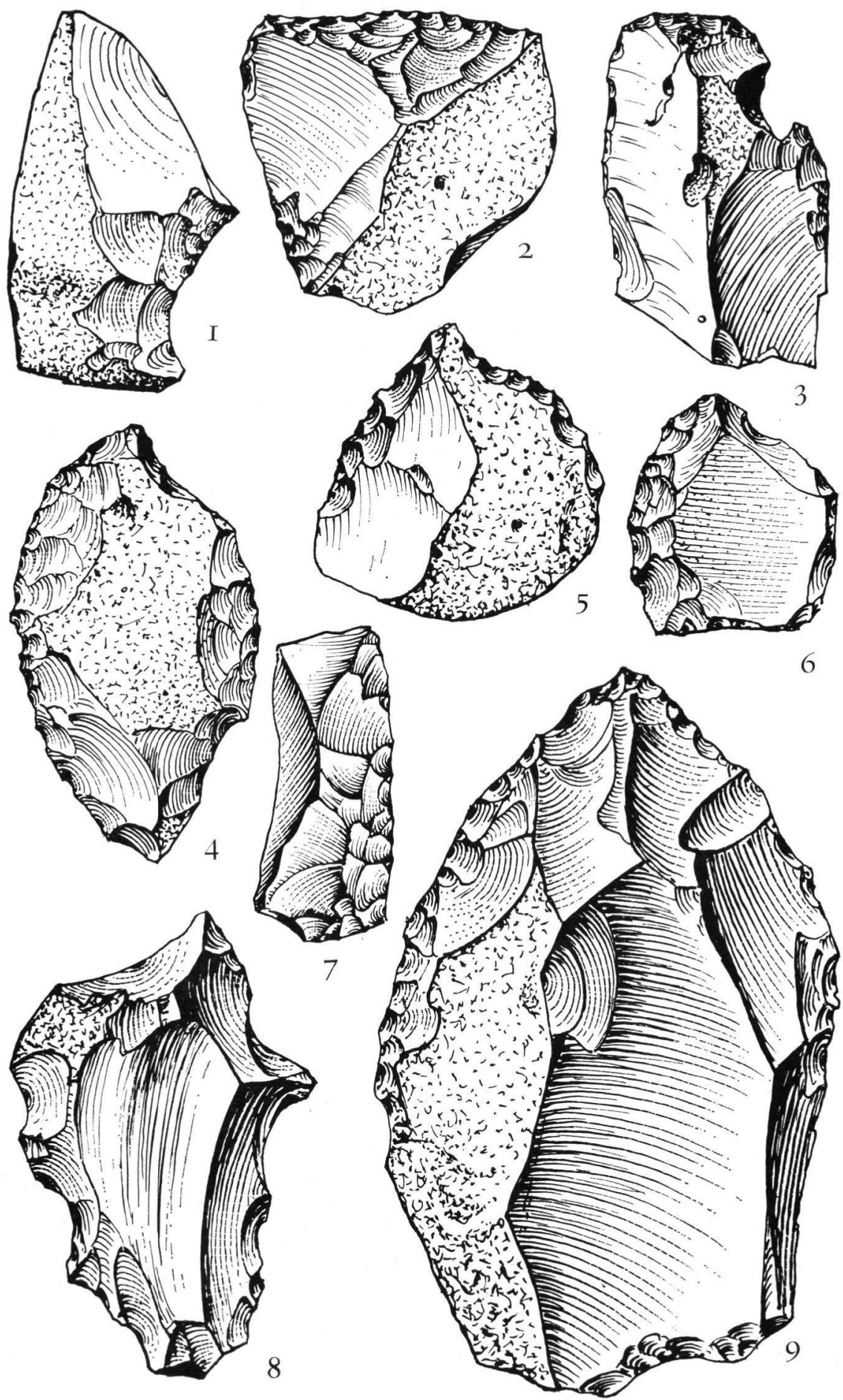

Fig. 5. Industrie de la couche 33. 2, 4, 5, 6 et 7, racloirs; 3, grattoir; 1, éclat avec encoche retouchée; 8 , éclat à becs et encoches de type clactonien; 9 , pointe. 


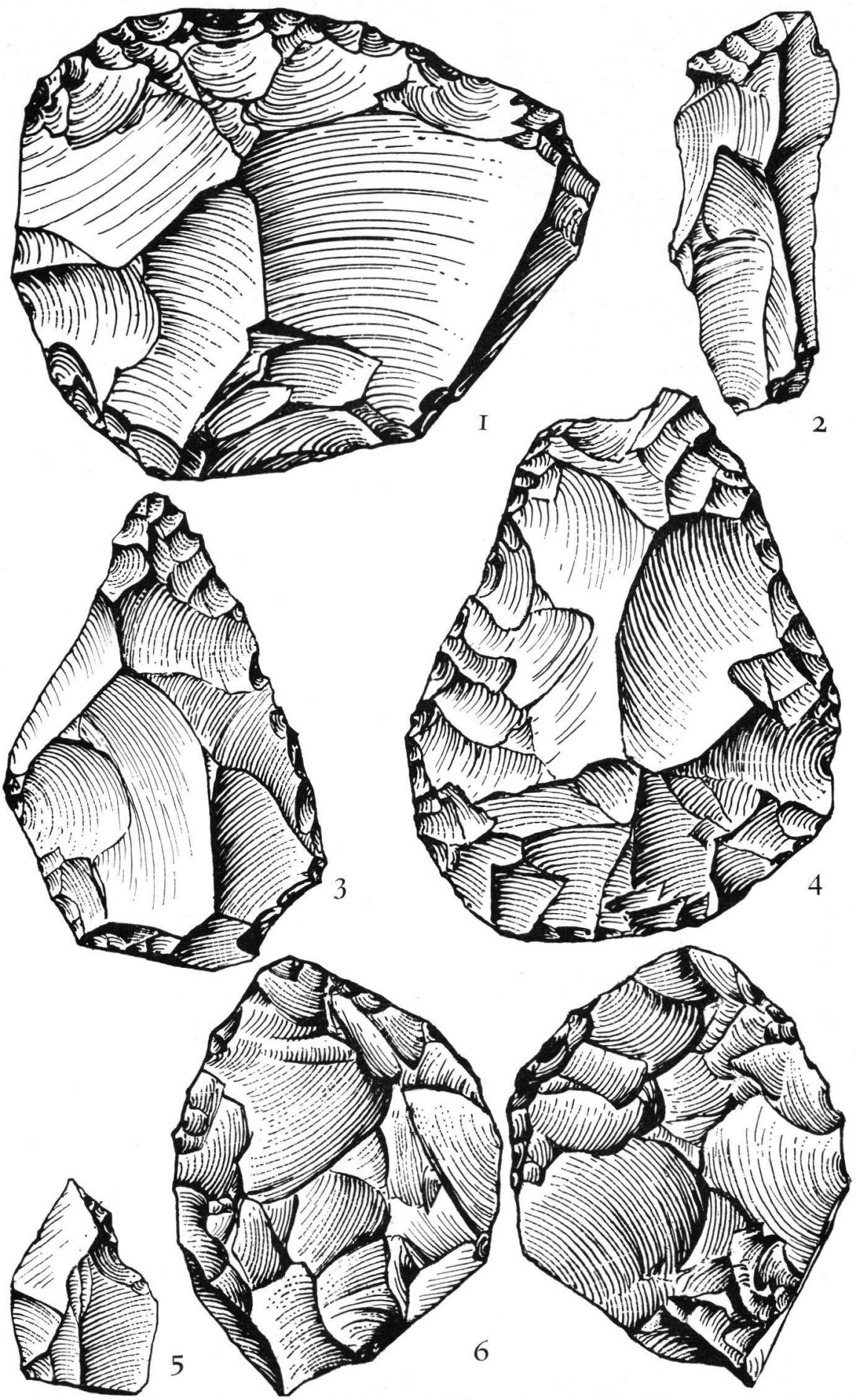

Fig. 6. Industrie de la couche 37. 1, racloir; 4 et 6 , bifaces; 3 , pointe; 5 , éclat avec encoche; 2 , éclat en forme de lame. 

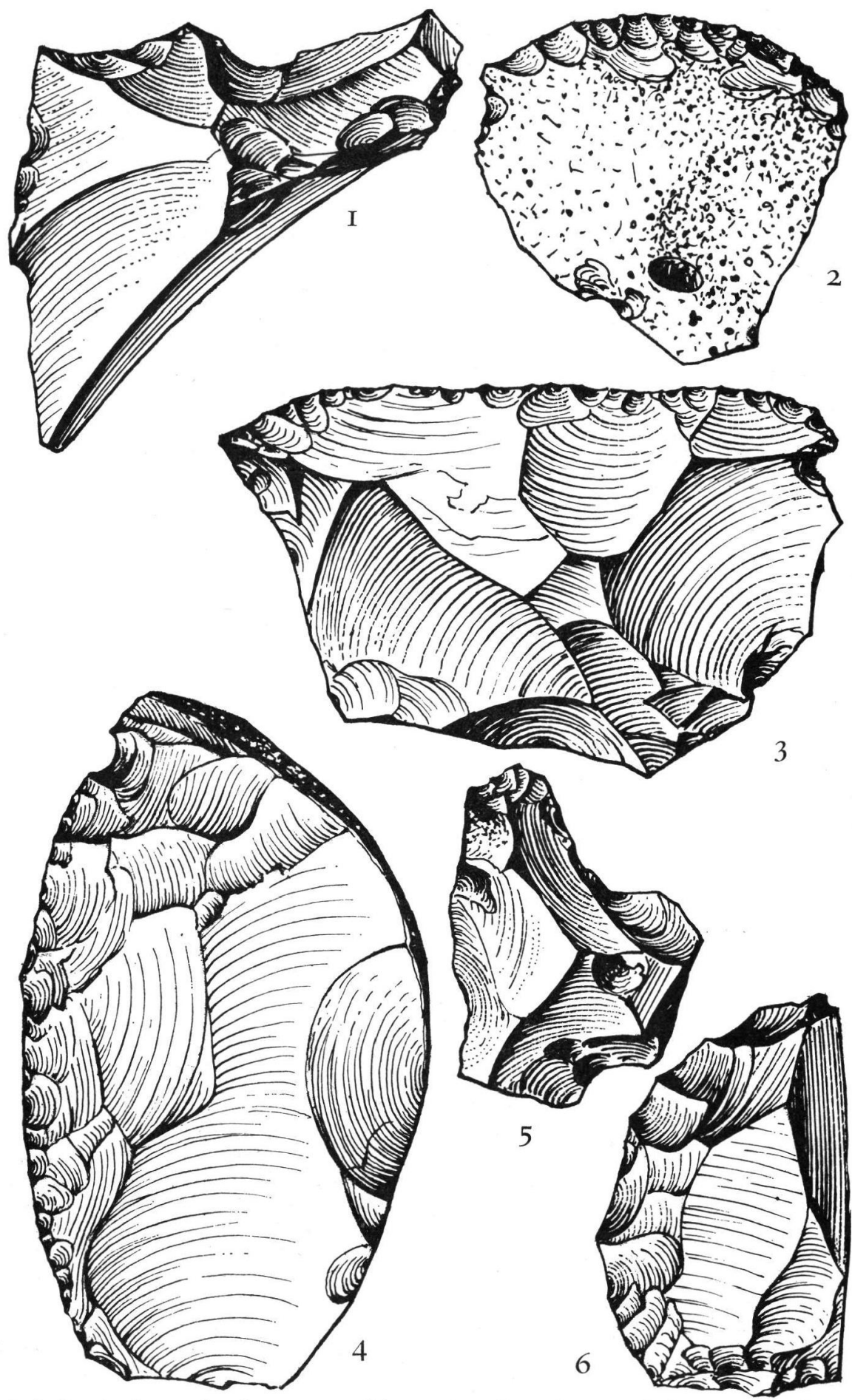

Fig. 7. Industrie des couches lacustres supérieures. 1 et 3 proviennent de la couche 40, les autres pièces de la couche $42.2,3,4$ et 6 sont des racloirs, 1 et 5 des éclats à encoches clactoniennes. 

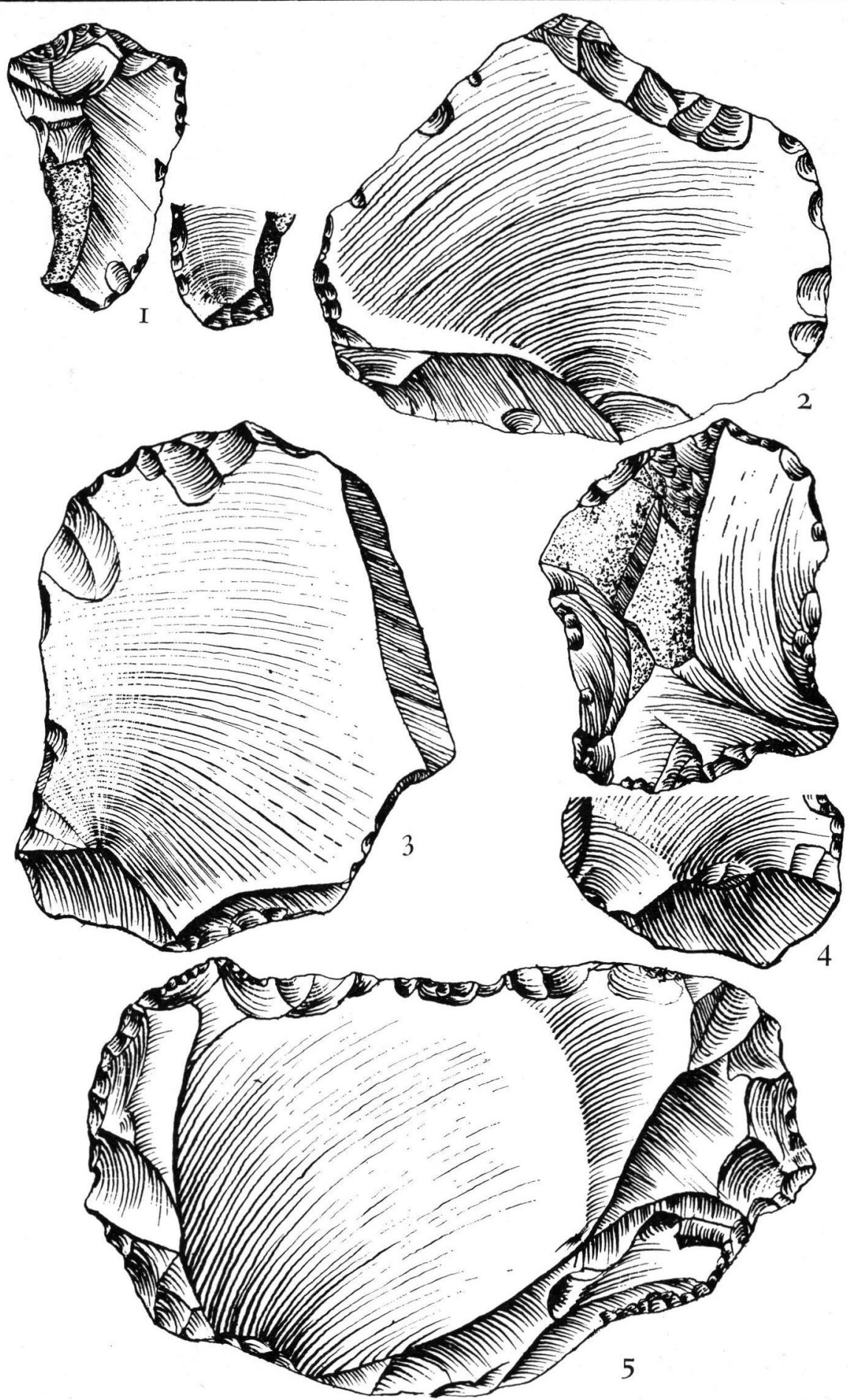

Fig. 8. Industrie de la couche 46, premier groupe. C'est une industrie de technique clactonienne, du type "Madonna del Freddo". 


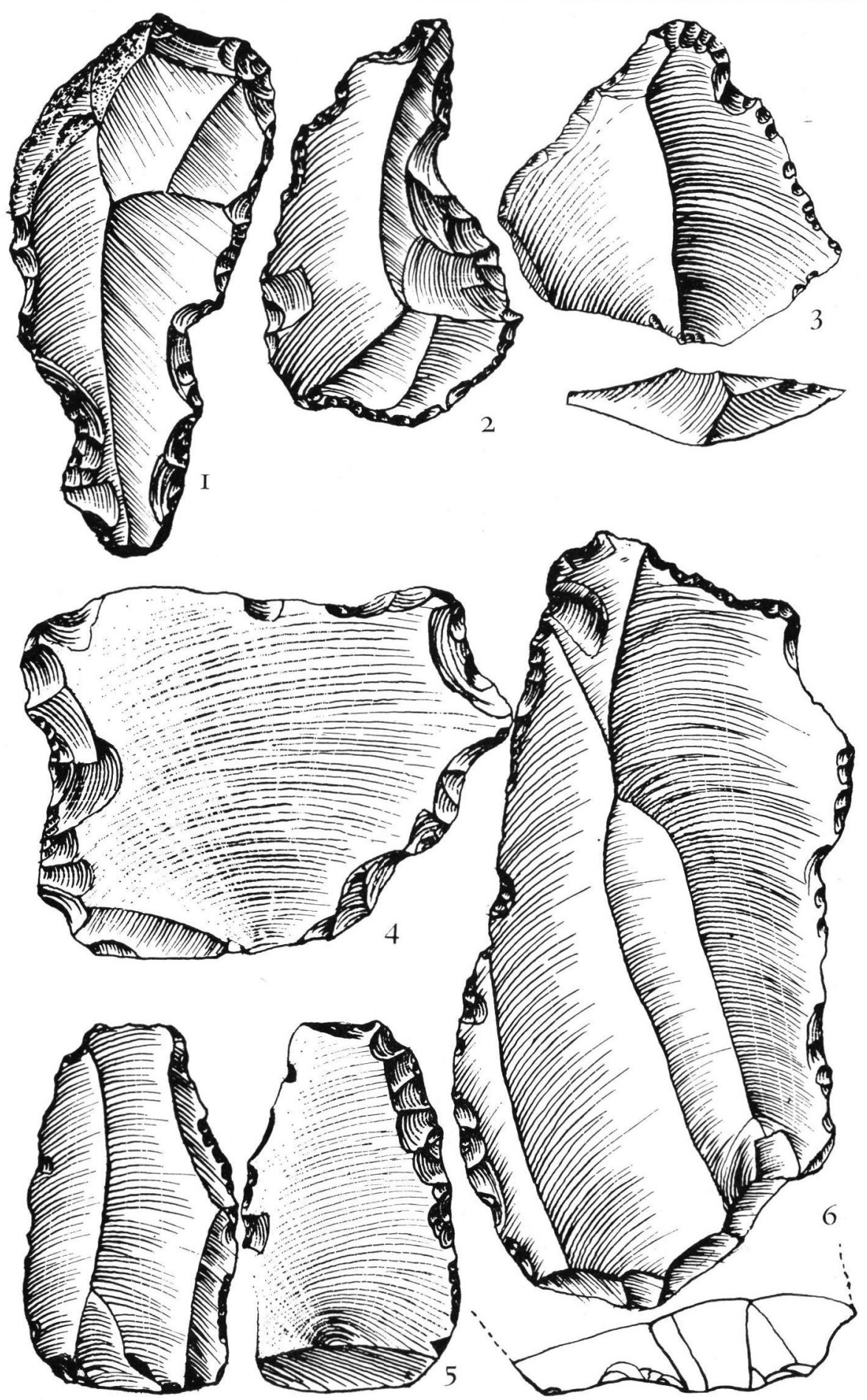

Fig. 9. Industrie de la couche 46 , troisième groupe. 5 et 6 , éclats laminaire retouchés; 3 , éclat à retouche denticulée; 4 , instruments à becs; 2 , perçoir; 1 , éclat pédonculé. 

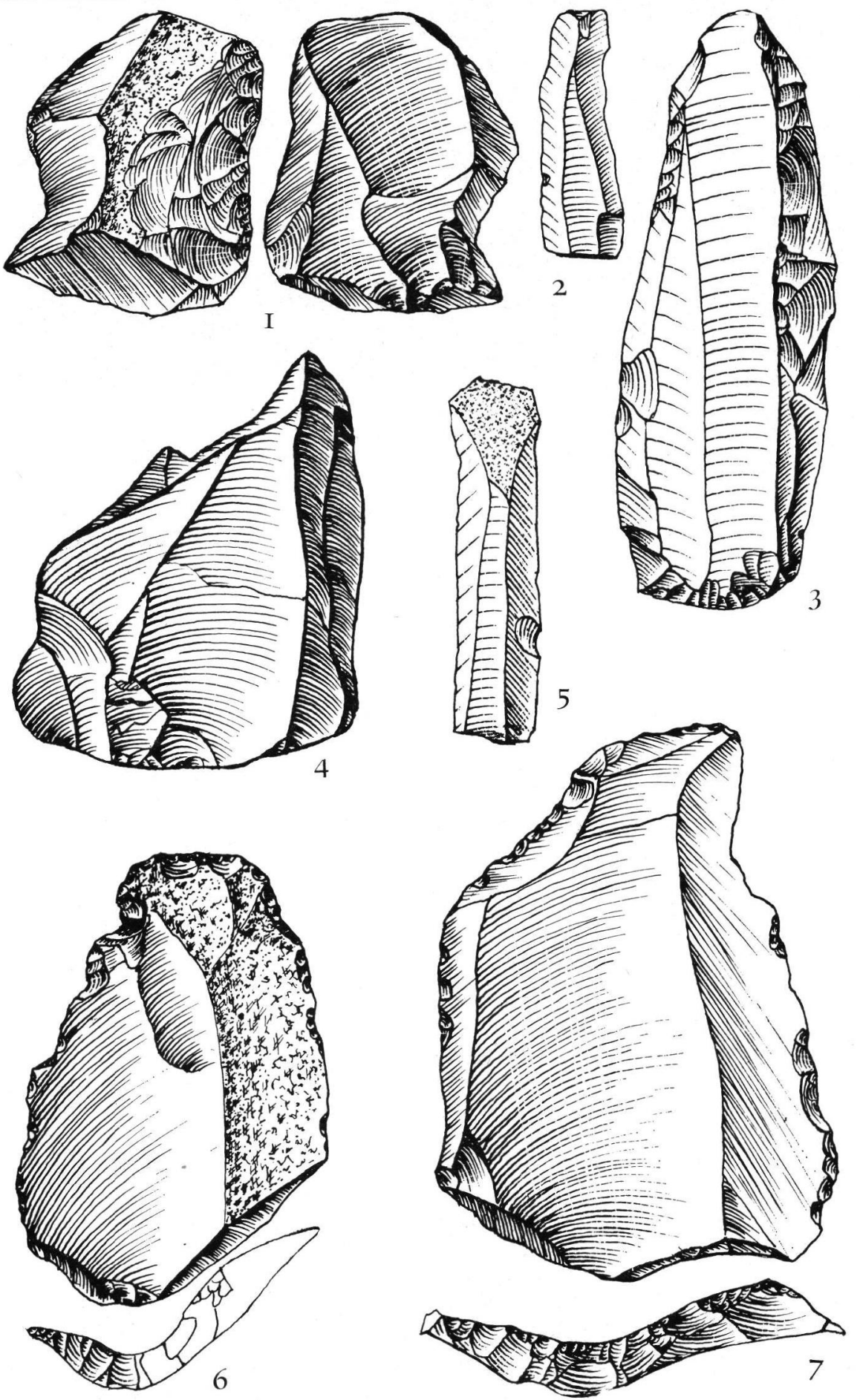

Fig. 10. Industrie de la couche 46, cinquième groupe. 6 et 7 , éclats en forme de lame; 2,3 et 5 , lames; 4 , nucleus; 1 , nucleus repris en racloir. 


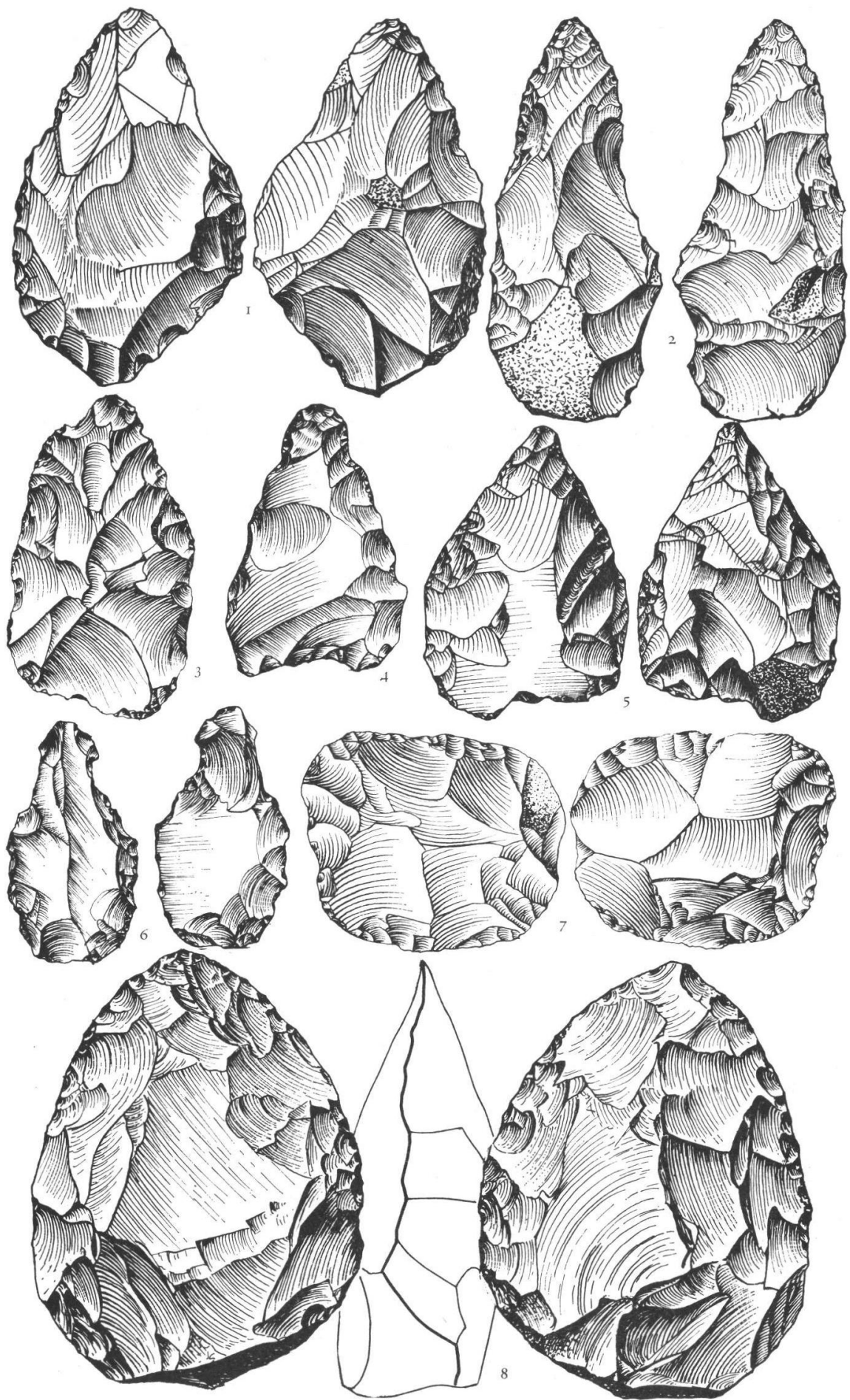

Fig. 11. Bifaces de la couche 46. Environ demi-grandeur naturelle. Voir texte. 
A) Les industries sur éclats se subdivisent, elles, en cinq groupes: I, le groupe archaïque comprenant des objets de type clactonien; II, le groupe formé d'outils dont les types se retrouvent dans les couches 20 à 42 ; III, le groupe des pièces de technique levalloisienne; IV, un groupe formé par des pièces du groupe III mais utilisées de seconde main; $\mathrm{V}$, une groupe d'instruments levalloiso-moustériens exécutés sur place.

Les 40 objets du groupe I sont en silex marron; ils ont une patine parfaite et présentent des talons à profil triangulaire, lisses et très inclinés, avec des bulbes très prononcés (figure 8). Il s'agit d'éclats de forme irrégulière, parfois très gros, et qui présentent des retouches marginales minces et irrégulières, souvent inverses ou alternes: leur typologie éloigne ces objets de ceux qui dérivent des couches inférieures, mais on peut les rapprocher de l'industrie clactonienne de la Madonna del Freddo, également en Abruzze adriatique (RADMilli 1964).

Les 35 objets du groupe II sont très patinés, et ils comprennent des racloirs transversaux et latéraux qui concordent parfaitement avec la typologie des pièces des couches 20 à 42 du dépôt.

Les objets du groupe III se subdivisent en éclats larges et courts à profil atypique ou bien irrégulièrement triangulaire ou quadrangulaire, et en grosses lames amincies vraiment laminaires (figure 9). Les éclats de forme atypique sont au nombre de 108, et 73 exemplaires ont une retouche denticulée, parfois alterne, alternante et inverse. Le talon est très variable: le type lisse, étroit, se retrouve sur 32 exemplaires; le talon lisse à angle presque droit se retrouve dans 28 cas; 4 spécimens montrent un talon à angle dièdre; 11 pièces sont à talon à larges facettes; sur 11 autres le talon a été emporté et sur 16 il n'est pas visible. Les lames, elles, sont au nombre de 84 avec une retouche denticulée et un talon lisse, étroit et peu incliné dans 15 cas, à angle droit dans 23 cas, tandis que 9 autres ont un talon à larges facettes. Il y a, en outre, 8 nucleus, dont quelques uns à profil discoïdal, 13 pièces avec encoches dont 4 larges se faisant rectilignes en bout, ce qui leur confère l'aspect de perçoirs, et enfin 12 pièces à becs.

Dans le groupe IV on trouve des objets du troisième groupe réutilisés, les parties reprises présentant une patine plus fraîche. La retouche est alors du type denticulé direct, inverse, alterne et alternante, rarement continue sur les bords.

Enfin les objets du groupe V (figure 10) comprennent 49 pièces à surface très fraîche, ce qui rend évidente la fabrication sur place. On compte 27 éclats lamellaires minces sans talon visible, 4 éclats et une lame avec talon à petites facettes, 7 éclats, et une lame à talon presque perpendiculaire au plan d'éclatement, 2 nucleus, 9 éclats laminaires retouchés en continuité ou en alternance.

B) Dans l'industrie des bifaces on distingue trois groupes d'objets (figure 11). Le premier groupe est fait de 10 amygdaloïdes cordiformes, fusiformes, triangulaires, avec des faces à profil convexe; le talon est basal, à deux plans convergents, ou bien convexe et avec cortex; la taille bifaciale à éclats larges, irréguliers et épais engendre des arêtes sinueuses; la patine apparaît plus ancienne que celle des deux autres groupes, et quelques exemplaires ont été repris.

Le deuxième groupe de bifaces comprend 19 amygdalö̈des présentant des affinités avec les bifaces de la couche 37 . Au troisième groupe se rattachent 24 specimens bifaces provenant pour moitié de cailloux ou de gros éclats: ils ont une face abrupte à profil convexe et l'autre face plate; le talon basal est souvent oblique, et le cortex envahit une partie de la surface de la face abrupte. A la préparation des bifaces sur éclats plats s'ajoute aussi une retouche imbriquée marginale qui rend les arêtes tranchantes et rectilignes. Dans beaucoup d'objets la face plane n'est façonnée qu'à la périphérie, et parfois l'enlèvement d'écailles n'est pas continu. Nous sommes donc en présence d'une industrie à bifaces qui concerne aussi des éclats, et où l'on peut distinguer des amygdaloïdes, des pointes et des racloirs. 
En r és u m é, d'après la situation stratigraphique et la typologie, ont peut distinguer à Valle Giumentina plusieurs industries du Paléolithique inférieur et moyen.

La plus archaïque est représentée par les outils des couches 20, 24, 30 et 33: c'est une industrie à éclats, éclats dont la forme n'est pas prédeterminée, et qui ont été transformés par retouche en racloirs, pointes, instruments à becs ou à encoches. Les éclats étaient généralement détachés du nucleus par un percuteur: il existe cependant des éclats dont le talon, très large et incliné, révèle l'emploi d'une enclume. Nous sommes donc en présence d'une industrie où la $\mathrm{tradition} \mathrm{cla} \mathrm{cton}$ ie $\mathrm{n}$ e est évidente. Elle a des analogies avec le Clactonien de High Lodge mais aussi avec l'industrie de la Quina. C'est pourquoi on peut la considérer comme un stade évolué du Clactonien italien.

La place qu'occupent les bifaces de l'A che uléen su périe u r dans le gisement (couche 37) prouve que cette industrie était en partie contemporaine du Clactonien évolué, mais le fait que les bifaces se trouvent dans cette couche ne signifie nullement que l'Acheuléen supérieur ait eu de l'avance, dans les Abruzzes, sur la Clactonien évolué. L'industrie de cette couche 37 a des traditions très différentes de celle des couches inférieures: en effet, en plus des bifaces, on trouve des outils sur éclats tellement minces qu'ils prennent l'aspect de lames véritables, à talon ponctiforme. Ces instruments ont été évidemment fabriqués par des hommes qui avaient atteint un haut degré de perfection dans l'exécution des bifaces.

L'industrie des couches $40-42$ montre un retour à la tradition propre aux hommes qui s'étaient succédés pendant des millénaires sur les bords de notre lac. Peut-être s'agit'il là des dernières manifestations des hommes de tradition clactonienne avant qu'ils quittent la zone lacustre en voie de déssèchement définitif.

Inversement, les industries en gisement secondaire de la couche 46 prouvent que d'autres populations, porteuses d'autres traditions techniques, s'étaient depuis longtemps établies dans la région de la Majella: les objets du groupe I sont, en effet, très semblables aux objets clactoniens de la Madonna del Freddo, comme nous l'avons signalé, ce qui démontre bien que les plateaux du Nord-Ouest de la Majella étaient parcourus par l'homme bien avant la formation du lac de Valle Giumentina.

Rappelons aussi que l'industrie du groupe III de la même couche est caractérisée par des éclats de forme variée et par de véritables lames grandes et épaisses. En plus du talon lisse, étroit et peu incliné, on voit apparaître le talon à larges facettes; la retouche est denticulée, du type direct, alterne, alternant; les encoches et les becs sont fréquents; quelques nucleus ont une forme plus ou moins discoïdale, et plusieurs présentent les caractéristiques propres aux nucleus préparés avec la te $\mathrm{chnique} \mathrm{le}$ vallo is ie n $\mathrm{ne} \mathrm{dit}$ "a rchä $\mathrm{qu} \mathrm{u}$ ", distincte de la technique levalloisienne vraie des outils du groupe V. Cette industrie est largement répandue dans les Abruzzes, surtout dans les stations de haute montagne, et elle se présente sous des aspects divers dont il reste à préciser la position. Un aspect particulier est celui des hautes stations de montagne, où elle acquiert une physionomie si particulière qu'elle peut être considérée proprement comme une "culture", culture que j'ai proposé d'appeler culture du Paléolithique abruzzais de montagne (Radmilli 1964). En effet, tout en faisant partie du groupe général des industries sur éclats de technique levalloisienne archaïque, elle a une physionomie propre dûe à la présence d'outils généralement de petites dimensions et de grattoirs, et à l'absence des gros éclats en forme de lame. A côté de ces éléments typologiques il existe, de plus, pour cette industrie, un rapport bien précis avec la climatologie du Quaternaire, puisque les chasseurs paléolithiques ne pouvaient atteindre les hauts plateaux de la montagne abruzzaise que pendant les interglaciaires, c'est à dire quand ils étaient libres de neiges permanentes.

Dans le groupe des outils bifaces de la couche 46 sont représentés divers autres hori- 
zons culturels, avec prédominance de pièces très évoluées appartenant à un Acheuléen supérieur, prélude au Moustérien de tradition acheuléenne.

III. Le gis ement des "Svolte"de Popoli

Pour encadrer chronologiquement les industries qui se sont succédées à Valle Giumentina, et en dehors de l'étude sédimentologique présentée dans la seconde partie de cet article, il est nécessaire d'examiner le gisement des "S v o $1 \mathrm{t}$ e" (mot à mot: les virages) de Popoli, découvert en 1955 par G. Leopardi (Leopardi \& Radmilli 1956; Leopardi, Pannuti \& Radmilli 1957) et fouillé en 1961. Il s'agit d'un plateau situé à 340-345 m d'altitude, à $3 \mathrm{~km}$ de Popoli, et qui a été récemment entaillé par un torrent. La fouille a mis à jour, de haut en bas, la succession stratigraphique suivante (fig. 12):

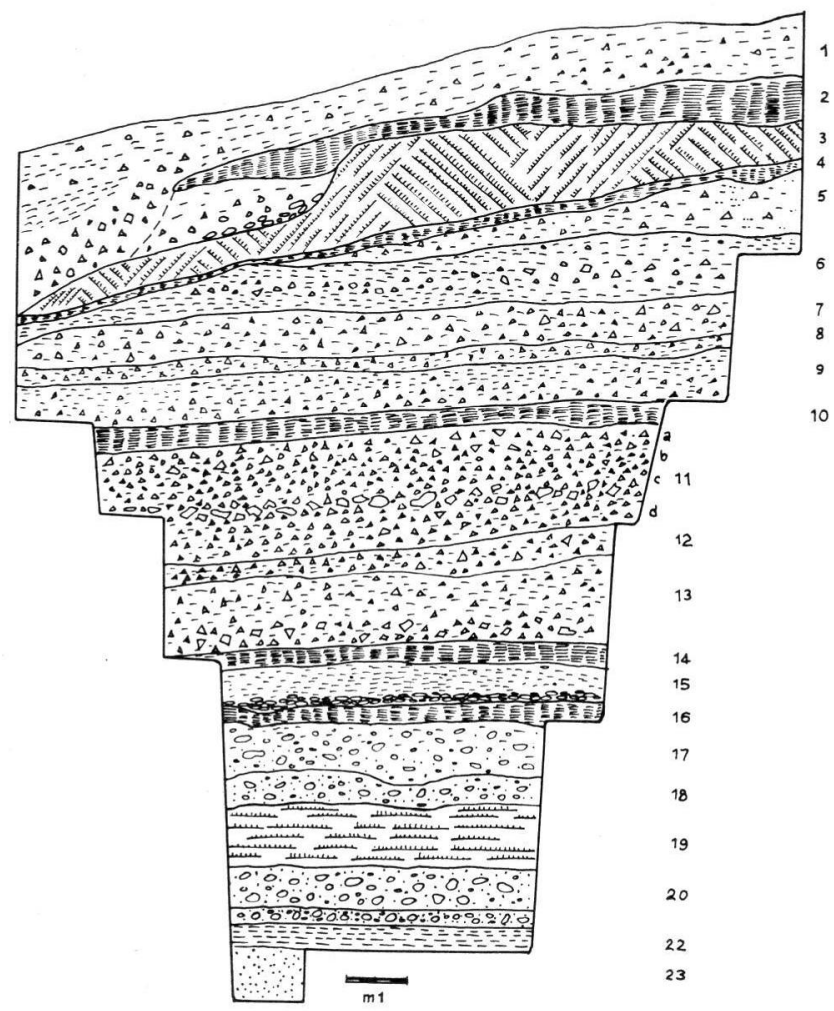

Fig. 12. Stratigraphie du gisement "Le Svolte", près de Popoli. Pour comparaison avec le gisement de Valle Giumentina.

- formation superficielle remuée par les travaux agricoles; épaisseur $50 \mathrm{~cm}$;

- formation terreuse brun clair mêlée à du gravier, comprenant de l'industrie du $\mathrm{P}$ a lé olithique moyen et supérieur; ép. $50 \mathrm{~cm}$ (couche 1 );

- formation argileuse sombre, avec industrie du $\mathrm{Pal}$ é olithique moyen; épaisseur variant de 5 à $60 \mathrm{~cm}$ (couche 2);

- formation calcaire blanc jaunâtre pulvérulente renfermant, dans sa partie supérieure, une industrie peu abondante du Palé olithique moyen; épaisseur de 5 à $150 \mathrm{~cm}$ (couche 3);

- formation argileuse brun sombre avec industrie peu abondante du $\mathrm{Palé}$ olith ique m o y e n ; épaisseur $25 \mathrm{~cm}$ (couche 4);

- formation de graviers mêlés d'argile brun clair et comportant une industrie le val1 o is o-moustérienne peu abondante; épaisseur variant de $5 \mathrm{~cm}$ à $100 \mathrm{~cm}$ (couche 5);

- formation argileuse brun-sombre avec intercalation d'un niveau de pierres et de gravier et une industrie levalloiso-moustérienne peu abondante; épaisseur de 25 à $100 \mathrm{~cm}$ (couche 6); 
- formation de graviers mêlés d'un peu d'argile jaunâtre renfermant une industrie le v a 1 -

1 o is o-mous tér i e n e peu abondante; épaisseur $70 \mathrm{~cm}$ (couche 7);

- formation de gravier mêlé d'argile sans industrie; épaisseur $25 \mathrm{~cm}$ (couche 8);

- formation argilo-terreuse brun sombre mêlée de graviers et renfermant une industrie levalloiso-moustérienne peu abondante (couche9);

- formation argileuse noirâtre avec empreinte d'os décomposés et une industrie $1 \mathrm{e} v$ a 1 lo is o-moustérienne peu importante (couche 10);

- formation de gravier se subdivisant, d'après la dimension des éléments en quatre niveaux $\mathrm{A}, \mathrm{B}, \mathrm{C}$ et $\mathrm{D}$, ayant restitué chacun des outils levalloiso-mous tériens; épaisseur $185 \mathrm{~cm}$ (couche 11);

- formation graveleuse mêlée d'argile brun rougeâtre renfermant une industrie $1 \mathrm{e}$ va 1 1 o is o-mous tér i e n n e peu abondante; ép. $40 \mathrm{~cm}$ (couche 12);

- formation graveleuse mêlée d'argile brun-sombre renfermant une industrie $1 \mathrm{e}$ v a $11 \mathrm{o}$ is omous térie n n e; ép. $135 \mathrm{~cm}$ (couche 13);

- formation argileuse brun rougeâtre avec os de cerf et abondante industrie $1 \mathrm{e} \mathrm{v}$ a $11 \mathrm{o}$ i s o mou s t ér i e n n e ; épaisseur $40 \mathrm{~cm}$ (couche 14);

- formation argilo-terreuse brun clair avec niveau caillouteux vers la base; os de cerf et de chevreuil; industrie le vallo is o-moustérie n ne ; épaisseur $65-70 \mathrm{~cm}$ (couche 15);

- formation d'argile sombre avec cerf, bouquetin, et industrie sur éclats de dépôt secondaire; ép. $30 \mathrm{~cm}$ (couche 16);

- formation de sable jaunâtre mêlé de graviers arrondis, avec industrie peu abondante en gisement secondaire; ép. $85 \mathrm{~cm}$ (couche 17);

- formation de graviers arrondis mêlés de sable jaunâtre, industrie peu abondante en gisement secondaire; ép. $40 \mathrm{~cm}$ (couche 18);

- formation calcaire blanchâtre avec restes de cerf et d'hippopotame, et industrie peu abondante en gisement secondaire; ép. $100 \mathrm{~cm}$ (couche 19);

- formation de graviers aux angles émoussés mêlés de sable jaunâtre, avec os de pachydermes, industrie sur éclats et bifaces de l'A c h e ulée n s u périe u r; ép. $60 \mathrm{~cm}$ (couche 20);

- formation de graviers aux angles émoussés mêlés de sable jaunâtre stérile; ép. $30 \mathrm{~cm}$ (couche 21);

- formation de sable quartzeux mêlé d'argile, stérile d'industrie; ép. $30 \mathrm{~cm}$ (couche 22);

- dépôt fluvio-lacustre sans industrie, épaisseur non vérifiée.

Certaines caractéristiques de ce gisement sont liées à la présence du lac de Popoli, postérieur au lac villafranchien, et qui se trouvait plus bas. C'est à dire que, tandis que ce lac existait encore, les cailloutis de la base de notre gisement étaient arrondis par l'action chimique aussi bien que par l'action mécanique des eaux dans lesquelles ils baignaient. Cela est clairement démontré par les caractéristiques des couches 23 à 17 , où il existe une alternance d'horizons déposés en eau profonde et en eau peu profonde, et d'horizons périodiquement découverts. La couche 16 s'est formée après le retrait définitif des eaux lacustres, et il est assez difficile de calculer à quelle durée correspond ce sol. Puis un torrent déposa les cailloux de la partie inférieure de la couche 15, laquelle est suivie, jusqu'à la couche 5 , par une alternance cyclique de dépôts détritiques provenant du versant et de sols véritables.

La discordance entre la couche 5 et la couche 4 correspond à une période d'érosion du versant, suivie de la formation d'un sol que la présence d'industrie moustérienne permet de rattacher à la glaciation würmienne. La formation de la couche 3, qui contient une industrie moustérienne, a été entaillée vers la gauche par un ravin où venaient aboutir, par glissement, les terrains des couches 3 et 2 et, enfin, la couche 1, avec ses industries du Paléolithique supérieur.

Dans la couche 20, en même temps que des objets de dépôt secondaire, on trouve un groupe d'outils exécutés sur place: il s'agit de bifaces travaillés avec la technique à retouche laminaire propre à l'A c h e u léen su périeur. Il n'est pas exclu que les artisans des bifaces aient aussi façonné les outils sur éclat de technique Levallois archaïque. Dans cette couche on trouverait par conséquent la preuve de la contemporanéité de l'industrie à amygdaloïdes de l'Acheuléen supérieur et de l'industrie sur éclats de technique Levalloisienne archäique. Il faut troutefois tenir compte du fait que l'un des bifaces a été réutilisé après retouche, ce qui nous entraîne à admettre la possibilité que l'industrie sur 
éclats soit plus récente. La zone a donc été recouverte pendant un certain temps par les eaux du lac qui ont déposé le calcaire de la couche 19; le gravier originaire du versant recommença ensuite à s'accumuler au bord du lac, ses éléments subissant un certain arrondissement, et de cette façon se constituèrent les couches 18 et 17 qui renferment des outils de dépôt secondaire et quelques éclats travaillés sur place d'après la technique levalloisienne archaïque. La même technique se retrouve aussi dans les quelques outils en place dans la couche 16 .

L'abondance des pièces dans les couches 15 et 14 , et la présence d'os carbonisés, prouvent une certaine permanence sur les lieux des peuplades qui travaillaient le silex avec une technique levalloisienne plus avancée: on y retrouve des éclats triangulaires typiquement de Levallois, des lames, et, pour la première fois, l'utilisation des plans de frappe préparés avec facettes petites et régulières; la retouche est généralement du type subimbriqué; peu d'objets montrent une retouche denticulée. C'est cette industrie formée d'éclats retouchés, de pointes, de racloirs, de nucleus irrégulièrement discoïdes, que j'ai appelée "levalloiso-moustérie nne“. Elle est présente jusque dans les couches supérieures, même lorsqu'elle n'est représentée que par peu de pièces. L'érosion du versant qui sépare la couche 5 de la couche 4 coïncide avec la période de l'arrivée dans la Conca Peligna des populations en possession de nouveaux outils. En effet on a trouvé dans les couches 4,3 et 2 et dans le paléo-ravin, en même temps que quelques objets levalloisomoustériens, des objets typiquement moustériens.

\section{Chronologie comparé des deux gisements}

Les gisements de Valle Giumentina et des Svolte de Popoli renferment donc une grande partie des industries du Paléolithique inférieur et moyen des Abruzzes. Mais il est possible de trouver un raccord entre les deux séries stratigraphiques, donc de reconstruire la séquence de ces industries.

Les bifaces découverts dans la couche 37 de Valle Giumentina et ceux de la couche 20 des Svolte appartiennent à la même culture: ils sont par conséquent contemporains ou peu éloignés dans le temps. Il en est de même pour les instruments du groupe $\mathrm{V}$, in situ dans la couche 46 de Valle Giumentina, et pour ceux des couches 15-14 des Svolte. Par conséquent la partie la plus récente de ce dernier gisement coïncide avec l'intervalle de temps pendant lequel s'est déposé, à Valle Giumentina, la couche 47, dépourvue, elle, d'industrie.

Puisque, aux Svolte, la couche 1 contient de l'industrie du Paléolithique supérieur, d’âge Würm III dans la littérature relative aux Abruzzes, il est évident que les couches inférieures 2, 3 et 4 se sont formées pendant la glaciation würmienne: raison pour laquelle l'industrie moustérienne est attribuée au Würmien. L'érosion entre la couche 4 et la couche 5 , et peut-être une petite partie des formations sous-jacentes, doivent être rapportées à la dernière période interglaciaire. La formation des couches $15-14$ est contemporaine de celle de la couche 46 de Valle Giumentina puisque les deux renferment une industrie levalloiso-moustérienne exécutée sur place. Mais la couche 46 de Valle Giumentina a tous les caractères d'un dépôt de solifluction: elle appartient donc à une période glaciaire. A cette même période glaciaire (Riss III ou Riss I ?) ${ }^{2}$ ) appartiennenet également les formations 15-14, formations dont les caractères ne sont pas contradictoires avec une telle interprétation puisqu'il s'agit de sols. L'érosion notable qui porte le numéro 44 dans l'échelle stratigraphique de Valle Giumentina a certainement coïncidé avec une période interglaciaire (ou un interstade du Riss ?).

Un argument valable en faveur de cette interprétation nous est apporté par les caractères du groupe III de l'industrie de la couche 46, dont on ne retrouve pas d'équivalent dans les dépôts sous-jacents (couche 43 à couche 20): il faut donc considérer cette

2) J. D. est d'une opinion différente: voir seconde partie de cet article et addendum. 
industrie comme postérieure à celle de la couche 42 et antérieure à l'industrie levalloisomoustérienne en place de la couche 46 . Il s'agit de cet ensemble de technique levalloisienne archaïque dont une partie doit remonter à un interglaciaire ou à un interstade, puisque des industries analogues ont été découvertes dans des stations de haute-montagne. Les formations de cette période devraient être représentées à Popoli par les couches 16-18, où existent des pièces de technique levalloisienne archaïque exécutées sur place ou en gisement secondaire.

La couche 43 de Valle Giumentina a été mise en place par solifluction: elle coïncide donc avec une période glaciaire, dont elle pourrait représenter la partie culminante, raison pour laquelle le dépôt lacustre sous-jacent se serait formé pendant la phase anaglaciaire (Riss 1 ou Mindel ?) ${ }^{3}$ ). La couche 20 des Svolte renfermant des bifaces exécutés sur place, doit être considérée comme contemporaine ou à peine postérieure à la couche 37 de Valle Giumentina, et l'indice d'émoussé du gravier joue en faveur de l'hypothèse d'un climat évoluant vers le froid.

Il résulte donc de ce qui précède que l'industrie moustérienne des couches 4, 3, 2 des Svolte appartient à la phase ancienne de la glaciation würmienne, vieille de 40 à 65000 ans. L'industrie levalloiso-moustérienne a débuté pendant la période glaciaire du Riss et a duré pendant toute la période interglaciaire Riss-Würm, et même pendant la période würmienne. La naissance de cette industrie pendant la période rissienne coüncide avec les résultats de A. C. Blanc pour la stratigraphie de Torre in Pietra où, justement, ce type d'industrie se trouve dans une formation sur laquelle vient s'appuyer un dépôt tyrrhénien (Blanc 1954, 1958).

Si l'association avec des bifaces de l'Acheuléen supérieur présente aux Svolte est exacte, les groupes d'industrie de technique Levallois se sont développés pendant la très longue période de temps comprise entre la période glaciaire du Levalloiso-moustérien et peut-être une partie de la période glaciaire précédente. L'industrie clactonienne évoluée du faciès de Valle Giumentina et celle de l'Acheuléen supérieur coïncident avec cette dernière période glaciaire (Riss I ou bien Mindel). Il n'est pas encore possible, actuellement, de situer l'industrie clactonienne plus ancienne de dépôt secondaire de la couche 46 (groupe I) et les pièces amygdaloïdes plus archaïques qui s'écartent notablement du Clactonien type Valle Giumentina et peuvent être considérées, en partie, comme contemporaines de l'industrie clactonienne découverte à la Valchetta Cartoni à Rome (Blanc, Tongiorgi \& Trevisan 1953).

\section{Deuxième partie: Sédimentologie du gisement ${ }^{4}$ )}

$$
1^{\circ} \text { Les conglomérats pré-rissiens A e t B (fig. 1) }
$$

I. Description des couches

Le dépôt le plus ancien (couche 1) repose directement sur le fond de l'alvéole lacustre, constitué de calcaires helvétiens (BALly 1954). Ce dépot est fait d'une vingtaine de mètres de galets bien arrondis (fig. 13) de taille extrêmement variable, puisqu'on observe, aussi bien, des blocs de $1 \mathrm{~m}$ de diamètre. La stratification est parfois entrecroisée. Certains galets sont cassés. Tout indique donc une mise en place par des eaux torrentielles tumultueses et irrégulières: nous sommes donc sûrs que le climat comportait de fortes pluies, qu'il n'était pas tropical humide (sinon il n'y aurait pas tant de galets) et que le relief avait déjà de fortes pentes.

La couch e 2 est une brèche très mal cimentée, d'une dizaine de mètres d'épaisseur. Elle est faite de cailloux à peine émoussés sur leurs arêtes, d'énormes blocs bruts qui

3) Pour J. D. l'âge mindélien est exclu.

4) Par J. Demangeot, Professeur à la Faculté des Lettres, Toulouse, France. 


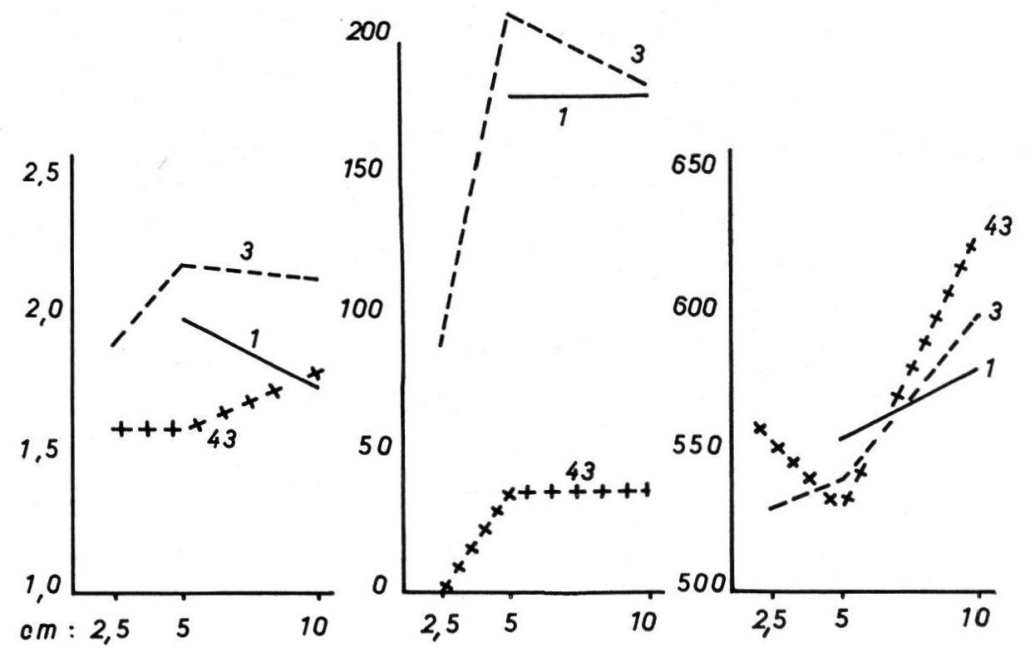

Fig. 13. Morphométrie de quelques cailloux de Valle Giumentina. Il s’agit de specimens récoltés dans les couches 1,3 et 43 . En abscisse diamètre moyen des specimens examinés. à droite indice de dissymétrie. Pour les définitions voir l'ouvrage de Cailleux et Tricart.

peuvent atteindre $3 \mathrm{~m}$ de diamètre, et d'une matrice de sables et de gravillons calcaires à angles vifs, le tout dans une disposition absolument anarchique. Ce dépôt a évidemment été étalé dans des conditions très particulières. Or il existe ailleurs, dans les Abruzzes, des mégabrèches très curieuses et qui peuvent lui être comparées: c'est la base des conglomérats de Pietracamela, les mégabrèches de Caramanico et de S. Eufema (qu'on a parfois prises, mais à tort, pour du matériel morainique (pe: Franchi 1919 et carte géologique 1:100000, feuille Lanciano) etc. Pour des raisons que nous exposons en détail dans notre étude d'ensemble des Abruzzes (Demangeot 1965), nous considérons ces mégabrèches comme les dépôts corrélatifs d'une importante poussée tectonique advenue en climat froid. Peut-être les cailloutis no. 2 de Valle Giumentina sont ils un équivalent de ces mégabrèches, quoique de faciès un peu différent ? Ce n'est qu'une hypothèse.

$\mathrm{L}$ a couche 3 est un poudingue peu épais ( 1 à $2 \mathrm{~m}$ ) mais suffisamment dur pour déterminer un ressaut topographique et localiser une cascade au fond du ravin. Les galets sont relativement homométriques. Bien qu'ils soient encore assez aplatis, leur émoussé (fig. 13) prouve qu'ils ont été convenablement roulés par l'eau (CAILleux \& TricarT 1959), l'aplatissement est en effet d'origine lithologique, les calcaires éocènes et helvétiens se débitant naturellement en plaquettes. Le ciment de ce poudingue est de nature calcaire évidemment, de grain fin, et il est teinté parfois de jaune ou de rose par une faible quantité d'oxydes ferriques qui lui donnent un aspect de mortadelle pâle. On a donc affaire à un dépôt torrientiel qui a été soumis à évaporation: on peut supposer alors l'action d'un climat à saisons contrastées, comparable au climat méditerranéen actuel.

Les cou ch es 4 à 8 (ensemble B) sont nettement discordantes sur la couche 3, et elles sont d'une tout autre origine. Il s'agit d'éboulis de calcaires locaux mis en place par gravité ou par solifluxion. Leur épaisseur est donc très variable. La preuve de leur origine est d'abord dans la forme même des fragments rocheux, parfaitement anguleux. Elle est aussi dans leur disposition au sein de la brèche. Tantôt les cailloux sont pressés les uns contre les autres, parallèlement à la pente, comme ceux qui glissent sur une surface gelée (éboulis ordonnés). Tantôt ils sont dressés comme dans une coulée de solifluxion: dans la couche 4 les trois quarts des cailloux, 76\% exactement sur la coupe étudiée, sont inclinés à plus de 45 degrés sur le plan de stratification. Tantôt ils sont disposés comme 


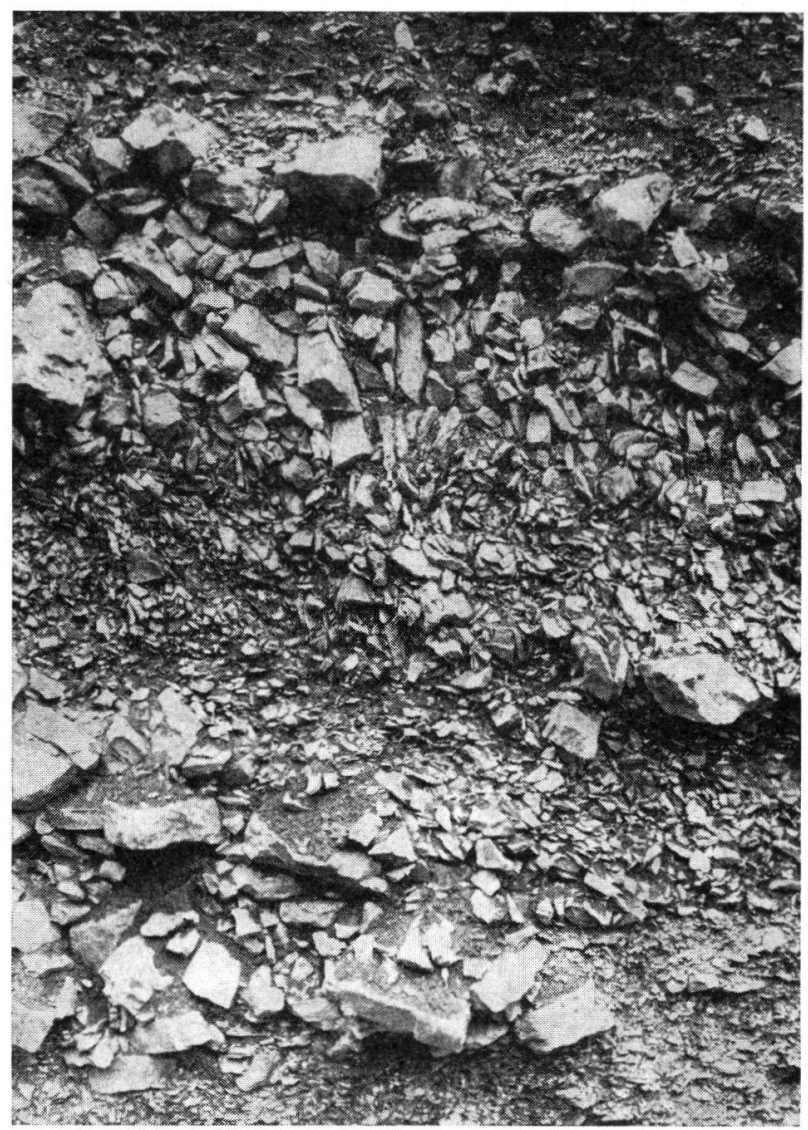

Fig. 14. Détail de la couche 4 de Valle Giumentina. Hauteur de la coupe: 1,50 m environ. Noter la forme et la disposition des cailloux. La matrice est une terre rougeâtre peu cohérente. Il s'agit évidemment d'une blocaille cryoturbée. Age: Mindélien. (Cliché J. Demangeot).

des rosettes ou des palmettes de cryoturbation. Il n'y a donc aucun doute possible: ces fragments ont été mis en place et immédiatement remaniés en climat périglaciaire. Ils sont donc contemporains d'une période glaciaire (Voir figure 14).

La matrice de ces brèches $B$ ne nous enseigne rien de très significatif. La fraction grossière consiste en grains de quartz non usés, en petits éclats calcaires et en grains de limonite détritique, limonite qui n'a rien de contradictoire avec un climat froid. La fraction fine est une argile rougeâtre, terreuse, peu cohérente. C'est elle qui a permis, localement, quelques brassages par cryoturbation. L'analyse de cette argile aux rayons $\mathrm{X}^{5}$ ) révèle une faible proportion de kaolinite et une prédominance d'illite: ce n'est pas surprenant puisque cette argile provient du lavage de sédiments marins (calcaires helvétiens et molasse pontienne) ou lagunaires (horizons supérieures de la molasse pontienne) situés à l'amont, vers la Majella.

Le sommet de ces brèches $\mathrm{B}$ présente un intérêt particulier car la matrice n'est plus argilo-terreuse, mais au contraire remplacée par un ciment dur, tellement dur qu'on de la peine à le casser au marteau. Cette véritable cuirasse a une cassure grenue et brillante, miroitante parfois comme celle d'un minerai métallique, de couleur noire vers la base et

5) Examen pratiqué obligeamment par M. ElHAI, Professeur à la Faculté des Lettres de Rouen. 
de couleur brun-marron vers le sommet. La masse même du ciment n'est pas compacte: on y découvre de petites vacuoles et de petites fissures emplies de calcite. Si son épaisseur était plus forte, car elle ne mesure que de 2 à $8 \mathrm{~cm}$ environ, cette cuirasse ressemblerait exactement aux cuirasses ferrugineuses de Guinée ou du Mato Grosso.

L'analyse détaillée de la cuirasse supérieure (no. 8) donne les résultats suivants ${ }^{6}$ ):

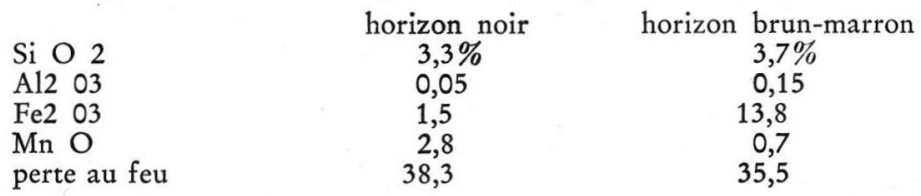

avec, partout, du $\mathrm{CaCO} 3$ en abondance, ce qui est parfaitement normal, et des traces de baryum, de magnesium, de titane, etc.

La comparaison avec les cuirasses tropicales n'est donc pas dépourvue de fondement. Mais il convient, à ce propos, de dissiper toute équivoque. Le terme de "cuirasse latéritique " serait totalement impropre, quisqu'il y a très peu de silice et pratiquement pas d'alumine: c'est bien le terme de cuirasse ferrugineuse qui convient. De plus il ne s'agit pas d'une cuirasse de plateau mais d'une cuirasse de versant localisée dans les cailloutis au niveau de l'ancienne nappe aquifère (p. e. MaIGnien 1958), chaque position de la nappe étant marquée par une cuirasse différente. Dans l'étude préliminaire j'avais distingué seulement deux cuirasses (no. 6 et no. 8): en réalité il y en a davantage, mais d'extension latérale limitée.

Le climat qui a déterminé la formation de cette cuirasse devait être à la fois suffisamment chaud et humide pour mobiliser le fer des argiles sous-jacentes, et suffisamment sec pour précipiter le fer, et surtout le manganèse: un climat tropical de transition, voire $\mathrm{sub}$ tropic 1 . Antérieurement j'avais songé à un climat désertique, ce qui était une erreur.

\section{Es sai de datation}

Il ne fait aucun doute que cet ensemble stratigraphique $A$ et $B$ soit $p r$ é-ris s i e n, puisqu'il est fossilisé par des couches $\mathrm{C}$ parfaitement datées du Rissien. Mais cet ensemble $A$ et $B$ est constitué de couches très diverses et suffisamment caractérisées pour que nous tentions d'y établir des subdivisions chronologiques.

a) La première précision nous est apportée par les brèches $\mathrm{B}$ encombrée d'argiles rougeâtres et scellées par plusieurs cuirasses ferrugineuses, car il ne peut s'agir que de brèches périglaciaires $\mathrm{m}$ indélie $\mathrm{n} \mathrm{n}$ es altérées par le climat rubéfiant de 1 'in $\mathrm{te} r$ Minde l- Ris s (Demangeot 1963).

Il est bien connu, en effet, que, dans la plaine du Pô comme dans la vallé du Rhône ${ }^{6 b}$ ), le Rissien a été précédé par un climat particulier qui a provoqué la ferretisation des moraines mindéliennes. (Pour la vallée du Rhône voir: Bourdier 1961). Il est sûr que ce climat a été chaud et humide (FRÄNZLE 1959) et non pas seulement tempéré comme on l'a cru parfois. Mais ce n'est que très récemment qu'on a mis en évidence le fait que le ferretto est une argile à tendance latéritique formée en climat quasi-tropical (GABERT 1962).

Or il serait bien improbable que le climat inter Mindel-Riss d'Italie centrale n'ait pas beaucoup ressemblé à celui de l'Italie du Nord, et même en plus chaud. De fait il existe dans les Abruzzes des dépôts comparables au "ferretto". J'en veux pour preuve la com-

6) Examen en lame mince par M. Mrchel, Professeur à la Faculté des Sciences de Grenoble; examen au spectromètre de masse par M. NiColas, Professeur à la Sorbonne; analyse chimique par M. Debiard, Laboratoire Municipal de Chambéry.

6b) Et comme dans les Pyrénées. Voir travaux de Mlle H. Alimen. 
position d'une "terra rossa" de Roccaraso (Abruzzes du Sud-Est) et celle d'une argile des environs d'Aquila (piano Dolfi). Voici les chiffres:

$\begin{array}{cc}\text { "feretto" } & \text { "terra rossa" } \\ \text { de la plaine du Pô } & \text { (Coccaraso } \\ \text { (GABERT 1962) } & \text { (Comel 1937) } \\ \text { de } 45 \text { à } 47 \% & 43 \% \\ \text { de } 24 \text { à } 31 & 21 \\ \text { de } 10 \text { à } 18 & 9\end{array}$

argile du
Piano Dalfi
(DEMANGeOT 1965)
$43 \%$
35
9

Si l'on ignore la position stratigraphique exacte de la "terra rossa" de Roccaraso, l'argile du Piano Dolfi, elle, est scellée par une brèche périglaciaire pré-würmienne. Il ne s'agit donc point de coïncidences.

Mais on objectera avec raison que, si la brèche périglaciaire $B$ est bien l'homologue des moraines mindéliennes, les cuirasses ferrugineuses du sommet ne sont pas le ferretto. Certes, mais elles en sont dérivées. Il est tout à fait probable que l'évolution climatique qui a mené du Mindel au Riss en passant par une phase chaude et humide "ferretisante", s'est close par une phase de demi-aridité "cuirassante": le fer ferreux de l'argile mindélienne (ce fer provenant de la glauconie ou des micas ou du grenat des sédiments miocènes) a dû être précipité sous forme ferrique lors de la phase de $\mathrm{l}$ a té $\mathrm{r}$ i t is a t i o n (=ferretisation), puis mobilisé à nouveau et concentré au niveau des nappes de versant lors de la phase de $\mathrm{c} u$ ir a s se me $\mathrm{n} t$.

b) Le second point est d'ordre taxonomique. Puisque, en Italie centrale, le terme de "Mindel" ou le terme de "Riss" ne peuvent avoir qu'une valeur approchée, nous allons tenter une corrélation avec le Latium où le regretté A. C. BLANC a jeté les bases d'une chronologie du Quaternaire local (BLANC 1957). Notre Mindel des couches 5 à 8 est-il l'équivalent de la "glaciation" Cassia ou bien de la "glaciation" Flaminia?

C'est l'épisode des ferretisations qui peut nous servir de point de repère. En effet il semble bien que le climat rubéfiant et chaud de l'inter Mindel-Riss ait produit sur le littoral de la Corse des altérations comparables à celles que nous connaissons en Italie centrale. F. Ottmann a décrit (Ottmann 1956) sous le nom de "n a p pes rouges des vallées a ctuelles" des dépôts rougeâtres, riches en oxydes de fer, étalés sur le plateau continental exondé, et ensuite recouverts de dépôts marins transgressifs à Cardiums. Cette transgression, dite d'Urbino, correspond exactement à ce que l'on appelait autrefois la transgression "milazienne": la nappe rouge est donc pré-milazienne. Or, selon A. C. BlANC, la période Flaminia est postérieure à cette transgression: donc, a fortiori, postérieure à l'épisode rouge.

Par conséquent, et si mon hypothèse de base est fondée, la phase des rubéfactions est inter Cassia-Flaminia: notre "Mindel" ne peut être que Cassia. Rien ne s'y oppose d'ailleurs: le climat de la Cassia a été très froid et les éruptions des volcans de Bracciano n'étaient pas commencées (BLANC, LoNA \& SETTEPAssi 1955) ainsi que va nous le montrer l'étude des minéraux lourds. De cette conclusion il s'ensuit: 1) que Cassia ne peut être Günz si elle est Mindel (!), et que par conséquent les effets du froid günzien restent à mettre en évidence dans le Latium; 2) que Flaminia, à supposer qu'elle soit représentée à Valle Giumentina, doit se trouver au-dessus des couches 5-8.

c) Si les brèches sont bien mindéliennes comme nous le croyons, les poudingues no. 3 qui se trouvent juste au-dessous dateraient de l'inter Günz-Mindel. En effet ils témoignent d'un climat beaucoup plus tempéré que celui de l'inter Mindel-Riss: or nous savons, par les pollens de Gelagna Bassa, dans l'Apennin ombrien (PAganelli 1959) que cet interglaciaire a précisément été tempéré, chaud et plutôt humide. Définition qui n'exclut pas un climat à été évaporant.

Restent à dater les cailloutis 1 et 2 . Si l'assimilation du conglomérat chaotique no. 2 avec les mégabrèches d'Aquila et Caramanico est correcte, elle donnerait un âge probable 
villa franchien su périe u r à ce conglomérat. En effet, dans la région d'Aquila les mégabrèches tectoniques sont posées sur le lacustre villafranchien moyen (lacustre à Elephas meridionalis et Hippopotamus major). Mais le cailloutis no. 1? Il est exclu qu'il remonte au Villafranchien moyen étant donné le contexte climatique. Mais il peut dater de la première phase froide et humide du Villafranchien. Ce n'est qu'une supposition, même pas une hypothèse. Quelles sont, par ailleurs, les relations entre ces deux couches basales de Valle Giumentina, et le poudingue fortement cimenté que l'on trouve au point le plus élevé du sentier Caramanico-Valle Giumentina? Elles sont postérieures, sans qu'on puisse préciser davantage.

\section{III. $\mathrm{Recherche} \mathrm{des} \mathrm{minéraux} \mathrm{lou} \mathrm{rds}$}

En collaboration avec Mme M. Ters j'ai recherché les minéraux lourds d'une quarantaine d'échantillons des Abruzzes, dont treize prélevés à Valle Giumentina (Demangeot \& Ters 1962$)^{7}$ ). A Valle Giumentina, en effet, la connaissance des minéraux lourds peut nous être utile de plusieurs façons.

D'une part, le bassin-versant étant actuellement dépourvu de molasse pontienne, il serait normal que les alluvions qui proviennent du lavage de ce bassin ne contiennent aucun des minéraux lourds de la molasse. Si elles en contiennent c'est que les conditions du drainage hydrographique ou la direction des vents ont subi des modifications importantes, ou bien que le bassin avait autrefois conservé des témoins de molasse, aujourd'hui disparus.

D'autre part, les éruptions volcaniques quaternaires du versant tyrrhénien ont projeté des cendres jusque sur le versant adriatique de la péninsule, où elles se sont incorporées aux dépôts alluviaux. Or nous connaissons à peu près la date du début de ces éruptions (voir Blanc 1936, Penta 1950, Rittmann 1956, Sabatini 1900, 1912, Stefanini 1936, cités dans Demangeot et Ters 1952): c'est le Villafranchien, si l'on ne tient compte ni des volcans toscans ni de l'île d'Ischia. Nous connaissons aussi la nature minéralogique des séries d'éruption: les volcans Vulsini, par exemple, sont à la fois plus acides et plus précoces que Roccamonfina, les Colli Laziali ne s'éveillent qu'après le Rissien, etc. On peut donc, en théorie, dater une couche quaternaire de l'Italie centrale par ses associations minéralogiques volcaniques.

Mais en théorie seulement, car, en pratique, l'identification des éruptions à distance, c'est à dire par des résidus qui ne reflètent pas fidèlement la composition minéralogique des laves, est difficile et souvent aléatoire. De plus, et pour des raisons qui nous échappent, les premières poussières volcaniques n'arrivent sûrement dans les Abruzzes qu'après le Villafranchien moyen, puisque le lacustre d'Aquila n'en contient pas, et peut-être même seulement après le Villafranchien supérieur.

Ces prémisses posées, les minéraux lourds contenus dans la matrice ou le ciment des couches 1, 3, 4, et 7 (voir tableau) autorisent les conclusions suivantes:

a) Ces quatre couches contiennent des minéraux volcaniques. Nous sommes donc sûrs qu'elles sont postérieures au Villafranchien moyen, ce qui est tout spécialement intéressant pour la couche 1 .

b) Les associations minéralogiques de ces couches, avec forte proportion d'augite aegyrinique et de mélanite, indiquent plutôt un volcanisme acide. Or, précisément, les seuls groupes volcaniques en éruption avant le Rissien sont ceux des Vulsini et des Cimini,

${ }^{7}$ ) La détermination et le comptage des minéraux ont été faits par Mme Ters, Maître de recherche au CNRS. - La question des minéraux lourds dans les Abruzzes, volcanique ou non, a été rapidement abordée par Chelussi (Giorn. Min. Christ. Petro., 1893, et Boll. R. Com. Geol. Ital., 1895), par Dainelli (Atti Lincei, 1906), par Moderni (Boll. R. Com. Geol. Ital., 1895), par SACco (Mem. Acc. Sc. Torino, 1907), par Sorrentino (Boll. Soc. Geol. Ital., 1934). Plus récemment L. Pederzolli-Gottardi a publié l'analyse d'un échantillon de sable à minéraux (Atti Soc. Tosc. Sc. Nat. 65,1958 , p. 15-24) mais sans en tirer de conclusions. 
Tableau 1

Les minéraux lourds de Valle Giumentina

Abréviations: $\mathrm{TML}=$ total des minéraux lourds; $\mathrm{MLV}=$ minéraux lourds volcaniques. $+=$ traces.

Source: Demangeot \& Ters, 1962.

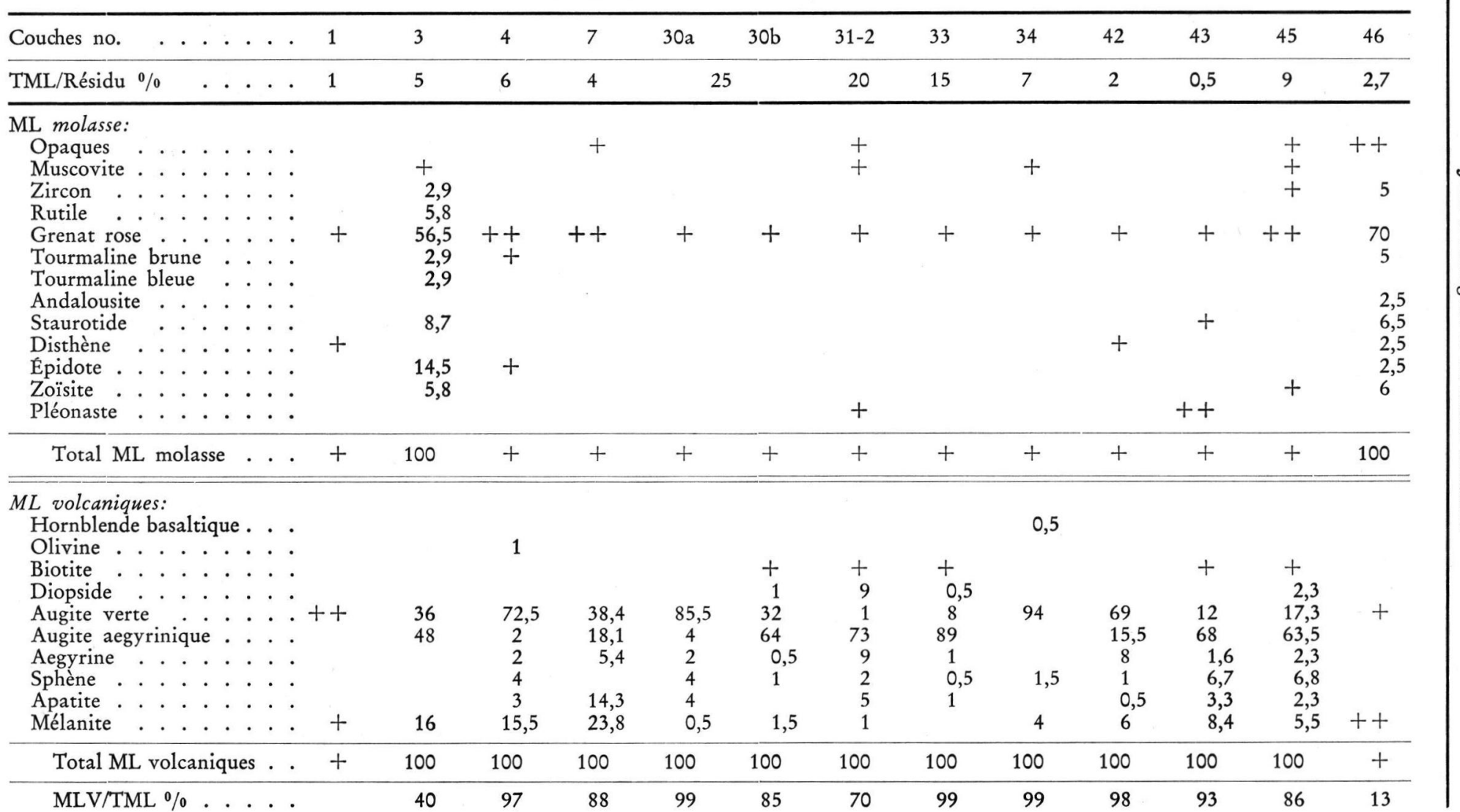


avec prédominance d'andésites et de trachytes: il ne peut s'agir évidemment d'une simple coïncidence.

c) La couche 3 contientdes quantités appréciables de minéraux lourds de la molasse $(60 \%$ du total des minéraux lourds), ce qui prouve que les apports détritiques avaient une origine assez lointaine; et ce n'est pas le cas des couches 4 et 7 , ce qui n'est pas surprenant. On ne peut s'empêcher, néanmoins, de penser aux caprices des vents locaux.

\section{2) Les couches rissiennes C}

Après un long intervalle de temps, impossible à chiffrer, la Valle Giumentina, encore encombrée des pierrailles et des cuirasses ferrugineuses, se remplit progressivement d'eaux stagnantes au début du Rissien: manifestement un barrage s'est créé à l'aval. Sur la nature de ce barrage toutes les suppositions sont permises, car il n'en subsiste actuellement aucune trace. L'hypothèse la plus vraisemblable est que le Vallone di Santo Spirito, où débouche normalement la Valle Giumentina, s'est empli d'alluvions au point de bloquer, latéralement, l'écoulement de Valle Giumentina. La cause de cet alluvionnement pourrait être climatique (période anaglaciaire). En tous cas les alluvions de cette époque n'ont été conservées qu'à Valle Giumentina, et la topographie générale a certainement beaucoup changé depuis le Rissien.

Il est à remarquer que les dépôts lacustres qui se sont accumulés ici sur $25 \mathrm{~m}$ d'épaisseur sont disposés par couches concordantes et peu épaisses sans que les plus récentes aient un faciès plus grossier que les plus anciennes, ce qui laisse supposer une surélévation du plan d'eau par petites saccades successives. On peut donc penser que les eaux n'ont jamais été bien profondes: $1 \mathrm{~m}$ ou 2 peut être. La Valle Giumentina était donc plus un étang qu'un lac véritable.

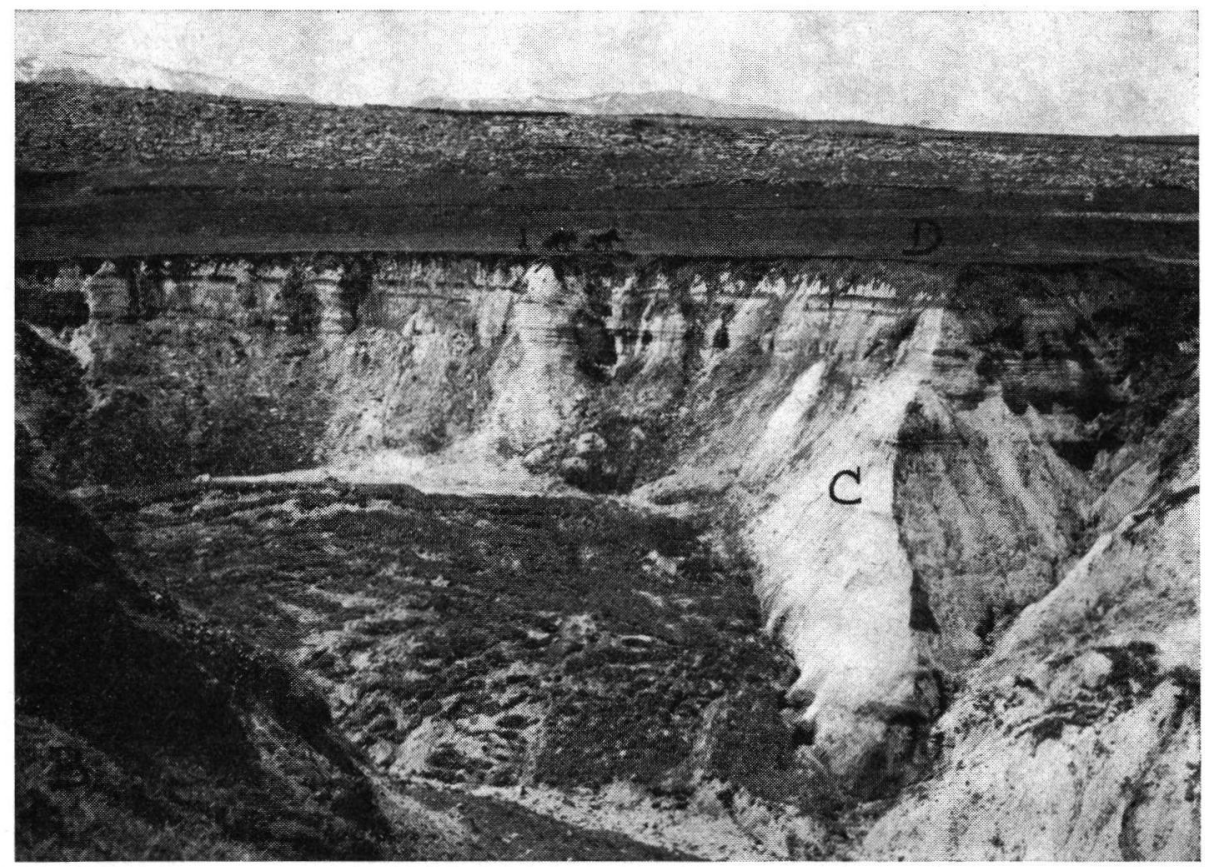

Fig. 15. Le lacustre rissien de Valle Giumentina. On voit nettement les horizons rissiens C alternativement clairs et sombres, la discordance 44 en dents de scie, et les limons würmiens D de couleur sombre. Le "flowage" qui a donné une coupe fraîche providentielle dans les couches à industrie est parfaitement reconnaissable. (Cliché J. Demangeot). 
Enfin il faut noter que le remplissage alluvial C ne s'est pas déposé seulement en milieu aquatique: les sables blancs et les marnes authentiquement lacustres (I) alternent avec des blocailles nivales (II) et même des paléosols noirâtres (III) de telle sorte que, en combinant les diverses méthodes de la sédimentologie, on peut parvenir à une vue nuancée du milieu géographique rissien.

\section{Les couches lacustres blanches}

Les couches blanches ou blanchâtres représentent plus des quatre cinquièmes de l'épaisseur totale du remplissage. Mais on constate, sur la coupe naturelle, qu'elles sont plus blanches vers le sommet du gisement que vers la base (figure 15).

Elles paraissent, au premier coup d'oeil, faites d'un sable calcaréo-dolomitique (2 à $0,02 \mathrm{~mm}$ ) très homogène, légèrement stratifié, noyé dans une pâte argileuse blanchâtre, voire une "farine" fossile. A l'examen on s'aperçoit que la partie fine est relativement peu argileuse: elle est faite, elle aussi, de calcaire, mais de calcaire à l'état de limon $(0,02$ à $0,002 \mathrm{~mm}$ ). Il s'ensuit que les carbonates peuvent atteindre $90 \%$ du poids du sédiment

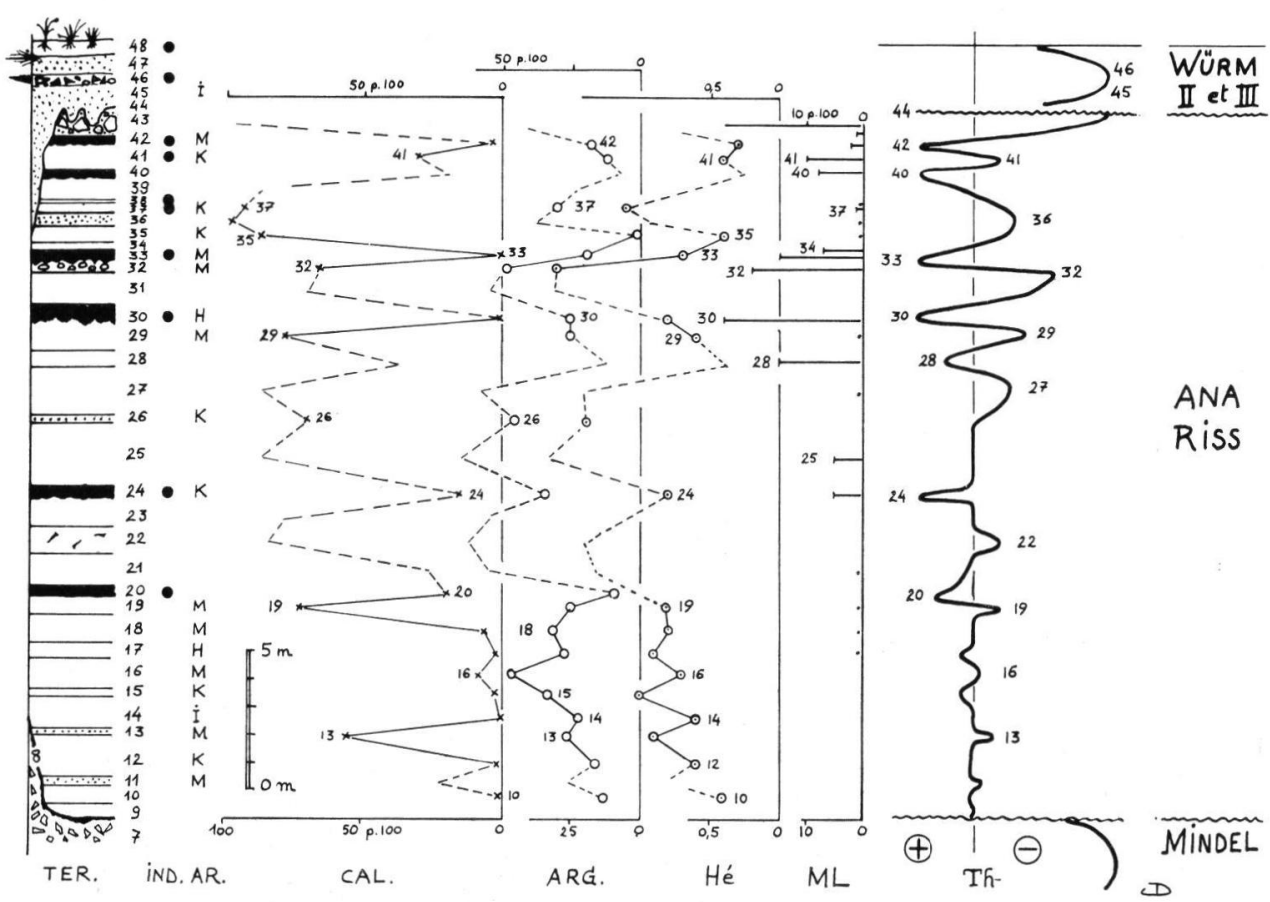

Fig. 16. Sédimentologie des couches lacustres rissiennes. Explication des colonnes, de gauche à droite: TER: succession des couches, avec leur numéro. Echelle de $5 \mathrm{~m}$ vers le bas à droite; en noir les paléosols argileux. IND: un gros point noir indique les couches à industrie. AR: nature minéralogique de l'argile prédominante ( $\mathrm{H}$ : halloysite, I: illite, $\mathrm{K}$ : Kaolinite, M: Montmorillonite). CAL: pourcentage de CO3 $\mathrm{Ca}$ dans le matériel "tout venant", d'après tableau de R. Olivieri, loc. cit. ARG: pourcentage d'argile granulométrique (particules inférieure à 5 microns) dans le matériel "tout venant", même source. Hé: indice d'hétérométrie de CaILleux (voir ici note 45) mesuré sur la courbe cumulative de la fraction inférieure à 30 microns, d'après R. OlrviERI, tableau 2. ML: pourcentage des minéraux lourds sur le résidu sableux décarbonaté, d'après Demangeot et Ters, loc. cit (de 9 à 23 pourcentage en nombre, de 24 à 43 pourcentage en poids). Th: courbe approximative des variations de la température, établie d'après les caractères sédimentologiques des couches. Dans toutes les colonnes la ligne tiretée indique une interpolation fondée sur l'examen macroscopique des sédiments. 
total ${ }^{8}$ ). La confusion entre le sens minéralogique et le sens granulométrique du mot "argile" explique pourquoi la courbe des argiles que l'on peut déduire des chiffres de Mlle Olivieri varie à peu près parallèlement à la courbe des carbonates (fig. 16)

Or l'abondance des calcaires finement devisés par voie mécanique est un indice certain de climat à gel saisonnier, alors que l'abondance des carbonates précipités ou construits est un indice de climat tiède ou chaud (p. e. Ložé 1957 et Demangeot 1965). Par conséquent, et si l'on considère toujours le même bassin fournisseur, la proportion des argiles minéralogiques doit automatiquement augmenter dans les alluvions lorsque le climat se réchauffe. D’ailleurs, pour peu que le climat s'assèche en se réchauffant, ce n'est pas seulement la proportion des particules argileuses qui augmentera mais aussi leur quantité absolue, car la sécheresse favorise la dégradation des affleurements argileux du bassin.

La différence de couleur entre la base et le sommet du remplissage, c'est à dire la différence de teneur en carbonates, peut donc être partiellement interprétée en fonction de la température qui régnait contemporainement à la sédimentation. L'apparence du dépôt, confirmée par l'analyse chimique, prouve donc que la base du complexe $\mathrm{C}$ a été déposée sous un climat moins froid que le sommet.

Cette interprétation est confirmée par la présence d'éclats de silex et de fossiles à tendance "froide" dans la partie supérieure du remplissage lacustre.

En effet on voit apparaître dans les couches 19, 22, 35 et 37 de nombreux et minuscules éclats de silex, de 0,5 à $1 \mathrm{~mm}$ de longueur. Or ils ne sont accompagnés d'aucuns graviers ni d'aucuns galets, de telle sorte qu'on ne peut les attribuer qu'à l'action au moins saisonnière du gel. Car le silex est gélif lorsqu'il a été "tectonisé" par les mouvements géologiques, ce qui est le cas ici.

L'autre confirmation vient des petits mollusques qui ont été récoltés dans la couche 37. Ce sont ${ }^{9}$ ):

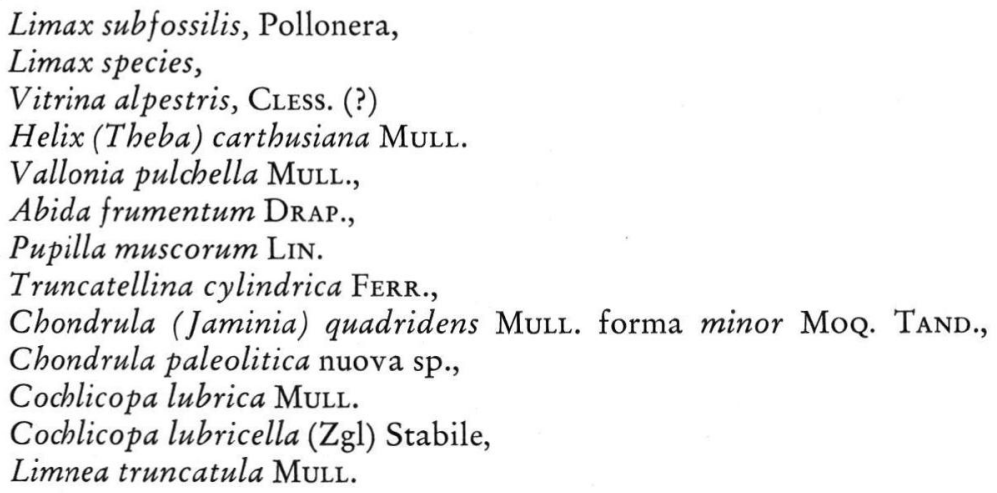

Or toutes ces espèces (sauf Limax subfossilis et Chondrula paleolitica, éteintes) vivent encore actuellement dans les moyennes montagnes d'Italie du Nord, d'où la conclusion de

8) L'analyse chimique et graulométrique du rimplassage rissien a été fait par Renata OLIvieri à l'Université de Modène et à l'Université de Bologne. Les prélèvements avaient été effectués sur le terrain par le Professeur Tongiongi, de l'Université de Pise. Voir Olivieri 1961.

La correspondance entre la numérotation des échantillon examinés par Mlle OLIVIERI et notre numérotation est la suivante. 1 de Olivieri $=43$ de Demangeot et Radmilli, jusqu'à ce que no $22=$ no 17 . Mais noter que $9=34$ et $33,10=32$ et $31,15=26$ et $25,17=23$ et 22 Ensuite A, B, C, D etc ... semblent être nos couches $16,15,14$ etc. ...

9) Détermination dûe à la compétence et en l'obligeance de M. SETTEPASsi, de l'université de Rome. 
M. Settepassi, qui les a déterminées: "L'ensemble de ces espèces permet d'établir que leur habitat physique et climatique était celui d'une montagne à climat tempéré froid“.

Le résultat est clair. La partie inférieure de la série lacustre a été déposé sous climat moyennement humide et moyennement froid, peu contrasté en tous cas; la partie supérieure a été déposée sous un climat également tempéré mais comportant des hivers accentués.. Donc, à ne considérer que les couches lacustres blanchâtres, il y a eu évolution vers le froid.

\section{Les caillout is "froids"}

Sur ce fond de climat tempéré évoluant vers le froid se sont superposées des crises de froid suffisamment violentes pour évoquer un climat périglaciaire.

On a déjà fait allusion aux petits éclats contenus dans les couches 19 et 22. L'offensive de froid se précise ensuite, en remontant la coupe, dans les couches 27,28 et 29. Certes rien, à l'oeil, ne semble les distinguer des autres couches blanches. Mais l'analyse chimique simplifiée révèle une forte augmentation de la teneur en $\mathrm{CaCO} 3$, teneur qui dépasse $70 \%$ (fig. 18); et, surtout, l'examen au microscope binoculaire du résidu sableux montre une proportion déjà appréciable de grains de quartzéolisés ${ }^{10}$ ):

- couche 27: 10\% des grains de quartz sont éolisés;

- couche 29: 54\% des grains de quartz sont éolisés;

(le complément à 100\% est fait de non-usés et de lustrés).

Or, à notre connaissance du moins, les roches situées à l'amont de Valle Giumentina ne contiennent pas de quartz éolisés, mais seulement des non usés et des lustrés d'origine marine. Ces grains éolisés postulent donc un sol nu, c'est à dire que la végétation ait été raréfiée soit par un excès de sécheresse soit par un excès de froid. La première solution étant exclue comme étant incompatible avec le contexte, il ne peut s'agir ici que d'une $\mathrm{c} r$ is e $\mathrm{de}$ froid, et de froid plutôt sec, ce qui recoupe très bien la signification des carbonates détritiques.

Une nouvelle crise climatique se manifeste dans la couche 32 . Là on trouve des galets de 2 à $8 \mathrm{~cm}$ de diamètre en moyenne, et passablement roulés, ce qui prouve l'activité d'un ruissellement concentré. Mais ces galets sont fendus, dans la couche, sans que les fragments soient déplacés, et leur surface est creusée de cupules de gélivation très caractéristiques. Enfin le cortège des signes de froid est complété par la présence de gros éclats de silex et l'abondance des carbonates: le climat était froid et humide sans aucun doute. Peut être la persistance du tapis nival explique t'elle l'absence de quartz éolisés.

Dans la couche 38 l'abondance des carbonates et l'apparition de quartz rondsmats typiques $(10 \%)$ indique une pointe de froid probablement sec.

Mais c'est, de loin, la cou ch e 43 qui est la plus intéressante. Elle commence par un mince lit de graviers calcaires ferrugineux et de gros éclats de silex (10 à $20 \mathrm{~mm}$ ). Puis vient, sur une épaisseur de $1 \mathrm{~m}$, un entassement désordonné de blocs de toutes tailles, les plus gros atteignant $80 \mathrm{~cm}$ de diamètre. Le ciment est blanc et pulvérulent. La conclusion est aisée: l'absence de stratification, la variété dimensionnelle des blocs, la fréquence des blocs dressés, le faible émoussé de chaque bloc (fig. 13), la nature du ciment et sa texture, tout montre qu'on est en présence ici d'une blocaille de solifluxion cryonivale, mise en place à l'état pâteux au cours d'une importante crise de froid périg l a cia i re. L'absence de quartz éolisés s'explique probablement, ici encore, par l'abondance de la neige.

10) On sait l'importance de l'état de la surface des grains de sable quartzeux. Voir par exemple CaILLEux 1942. 


\section{Les paléosols noirâtres}

Les couches 16, 20, 24, 30,33,40,42, tranchent par leur couleur sombre sur l'ensemble du remplissage rissien. Ces couches sont faites d'une argile brun-noirâtre, très grasse au toucher lorsqu'elle est humide, mais grumeleuse et se divisant en prismes lorsqu' elle est amenée à se déssécher. On sent aussi, sous le doigt, une petite partie de sable et même quelques graviers aigus. Parfois, mais rarement, il y a encore des feuilles d'arbres et des fragments ligneux, mais pratiquement indéterminables. Chacune de ces couches sombres est limitée à sa face inférieure par une surface irrégulière, tandis que la face supérieure est plane et horizontale.

Ces couches sombres sont donc, selon toute vraisemblance, des paléosols installés sur le fond même de l'étang en voie de déssèchement temporaire.

Que la surface de ces paléosols ait été réellement exposée à l'air libre ne fait aucun doute puisqu'ils ont servi de voie de passage aux animaux et aux hommes préhistoriques. Mon collègue le Prof. Radmilli a, en effet, identifié des restes de Cervus elaphus dans la couche 16, d'Ursus spelaeus dans la couche 30, de Cervus sp. dans la couche 40, mais jamais de fossiles aquatiques. Et c'est surtout à la surface de ces anciens sols qu'il a récolté l'intéressante et abondante industrie lithique qui caractérise et qui contribue à dater ce gisement: cinq des huit couches à industrie sont des paléosols, et cela n'est pas surprenant.

Des feuilles d'arbres, des Mammifères forestiers, la présence de l'Homme, tout concourt à prouver que ce climat était un assez bon climat ${ }^{11}$ ). Mais nous ne saurions nous contenter de cette définition vague, et nous demanderons des précisions aux argiles que continennent ces sols.

L'ét ude des a rgiles a été menée indépendamment de nous, et à l'aide des techniques les plus modernes, par Mlle Olivieri (Olivieri 1961). Il en ressort que les couches $12,14,15,24,26,35,37$ et 41 contiennent de la kaolinite et de l'illite; que les couches $11,13,16,18,19,29,32,33$ et 42 contiennent aussi de la kaolinite et de l'illite, mais, en outre, de la montmorillonite; que les couches 17 et 30, enfin, contiennent de l'halloysite - allophane. Pour trois de ces couches les proportions exactes ont été calculées:

- couche 29: montmorillonite $50 \%$; kaolinite $20 \%$; illite $30 \%$;

- couche 17: halloysite $70 \%$; illite $30 \%$;

- couche 14: kaolinite $30 \%$; illite $70 \%$.

Il est toujours très délicat de tirer des conclusions de la nature des argiles: la kaolinite et l'illite sont certainement remaniées à partir des sédiments calcaréo-marneux du bassin, de telle sorte qu'elles peuvent nous renseigner sur les conditions de la sédimentation au Miocène, par exemple, mais pas au Rissien. Toutefois Mlle Olivieri suggère que l' $\mathrm{h}$ a 1 loysite pourrait être mise en relation avec une certaine acidité des eaux courantes, cette acidité étant elle-même provoquée par la présence d'humus, donc de végétation, dans le paysage. Bien qu'il n'y ait pas une correspondance frappante entre les signes de climat tempéré et la présence d'halloysite, l'explication paraît plausible: les paléosols 17 et 30 sont pauvres en carbonates mais riches en halloysite.

Il me semble, de plus, qu'il ne serait pas déraisonnable d'établir une corrélation entre la montmorillonite et les paléosols. Les pédologues nous enseignent, en effet, que la montmorillonite est souvent liée aux sols forestiers brun-noirs, humifères, et de fort $\mathrm{pH}$. Or nos sols fossiles sont brun-noirs, humifères, et leur $\mathrm{pH}$ atteint 7,8 quand ils contiennent de la montmorillonite. Peut-être étaient-ils, à l'origine, des "mulls" à humus doux, sous végétation caducifoliée.

11) Le prof. Tongiongi, de Pise, et le prof. Elhaï, de Rouen, ont séparément recherché les pollens de ces couches sombres, mais sans résultats. Il est bien possible que les oxydations qui accompagnent la pédogenèse aient détruit les pollens. 
Bref un grand nombre de signes nous autorisent à penser que le $\mathrm{cli} \mathrm{m}$ a $\mathrm{t} \mathrm{con}$ t e $\mathrm{m}$ porain de ces paléosols permettait une végétation forestière t e m pér é e. Il est donc normal que nous trouvions dans ces paléosols peu de carbonates détritiques et pas du tout de quartz éolisés.

Mais, quand il est question de sols, il faut distinguer entre la mise en place du dépôt et son évolution proprement pédologique. Il ne semble pas, ici, que les conditions de formation du support minéral aient été très différentes des conditions de sa transformation. Une température moyenne, des pluies fines et régulières, tel semble avoir été le climat qui a immédiatement précédé la pédogenèse. Autrement on ne s'expliquerait pas l'homogénéité granulométrique du sédiment: homogénéité visible à l'oeil nu de la fraction la moins fine, homogénéité de la fraction fine démontrée par l'indice d'hét éromé tri e de Carldeux (fig. 16): il est éiident qu'un ruissellement irrégulier n'aurait pas assuré un aussi bon triage des particules (fig. 17).

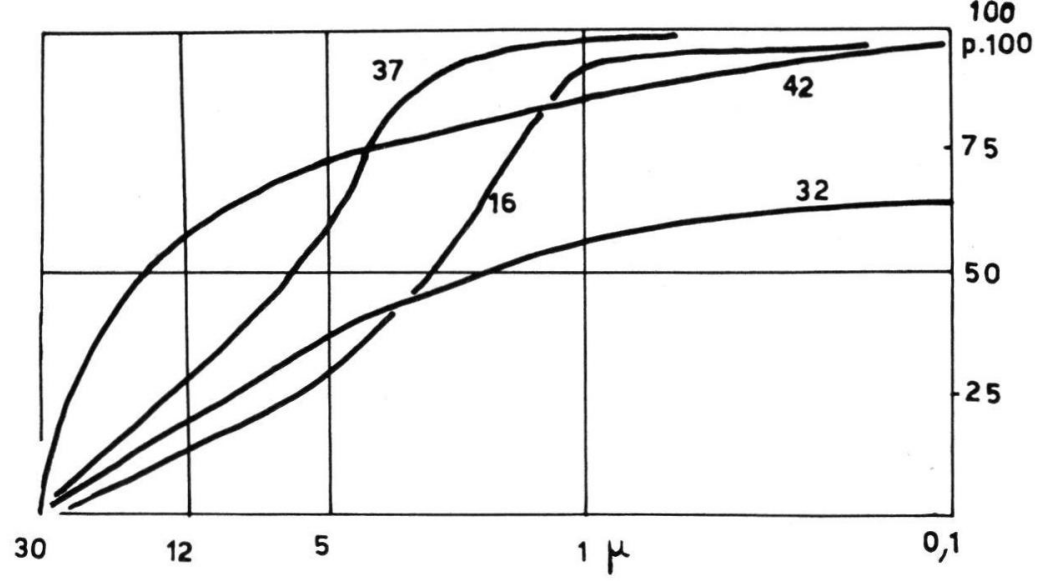

Fig. 17. Granulométrie fine de quelques couches rissiennes. Courbes cumulatives des fractions inférieures à 30 microns, d'après les chiffres fournis par R. Olivieri, loc. cit. La grande majorité des 19 échantillons examines ont une courbe intermédiaire entre la courbe de l'échantillon 42 et celle de l'échantillon 32 . Seules 16 et 37 dénotent un triage plus achevé.

\section{L'évolution climatique anaris sienne}

En regroupant les résultats de ces analyses successives sur le graphique de la figure 16 , on obtient une sorte de courbe climatique tout à fait suggestive, et qui permet de se faire une idée assez précise de l'évolution climatique rissienne, de la couche 9 à la couche 43.

Première observation: les signes de froid les plus nets et les plus nombreux sont groupés en haut de la figure: on a donc sous les yeux la courbe d'une période d'englaciation, c'est à dire d'un a $\mathrm{n}$ a g l a c i a i re. Peut on écrire, comme je l'ai fait autrefois, que la partie la plus basse serai d'un interglaciaire, d'un "Sicilien" conventionnel (conventionnel parceque sans signification marine)? Il ne semble pas. Le Prof. Woldstedt, qui a reproduit la coupe de notre gisement dans son Traité (WoldstedT 1958), fait observer que, étant donné l'homogénéité d'ensemble du milieu décrit, l'évolution a dû être progressive. J'accepte volontiers cette objection, qui est conforme au bon sens, et je considère que cette courbe est plutôt celle de l'an ag la cia ir e rissien ${ }^{12}$ ). Mais nous essaierons plus loin de savoir de quel Rissien il s'agit exactement.

12) D'ailleurs il est parfois bien difficile de préciser la différence entre la fin d'un interglaciaire et le début d'un anaglaciaire... 
Seconde observation: la courbe prouve que le froid s'est installé par crises successives. Dans la mesure où l'épaisseur des couches lacustres est approximativement proportionnelle au temps, il semble bien que la pério dic it é de ces pointes de froid a été relativement régulière, à l'exception, peut-être, d'une pause entre les couches 22 et 27 . Sur la base d'une dizaine de refroidissements au cours d'un ana-Riss que l'on peut évaluer très grossièrement à 20, 30 ou 40 millénaires, on aurait donc un intervalle approximatif de 2 à 4 millénaires entre chaque pointe froide. Par contre l'a m plit u de des crises augmente très nettement à partir de la couche 27 . Il est notable, également, que chaque poussée de froid est précédée ou suivie d'une poussée thermique en sens inverse et au-delà du climat "moyen". Là encore la partie supérieure de la courbe est particulièrement démonstrative.

Troisième observation: les crises de froid sont accompagnées d'une augmentation d'humidité (adocéanique), tandis que les phases tempérées sont de nuance sèche.

Toutes observations qui nous amènent à conclure que le glaciaire rissien s'est installé non par un abaissement graduel de la température mais pardes crises de froid océanique de violence croiss a nte. Mais, si nous en croyons les témoignages archéologiques, l'Homme clactoacheuléen paraît s'être adapté à ces crises brutales, puisqu'on trouve des silex taillés même dans la couche 38, pourtant déposée en climat très rude. Le site de Valle Giumentina ne semble avoir été vraiment abondonné qu'aux temps périglaciaires contemporains de la couche 43 .

\section{Les minéraux lou rds}

Les couches rissiennes sont particulièrement riches en minéraux lourds, puisque la proportion de ces minéraux sur le résidu sableux passé à l'acide peut avoisiner $25 \%$, ce qui est énorme.

Ce n'est pas aux minéraux lourds de la molasse qu'on doit ces fortes proportions, car ils sont pratiquement absents du spectre minéralogique, et cela probablement pour des raisons de changement de drainage. Mais c'est l'activité volcanique du versant tyrrhénien qui est responsable de ces proportions anormales. En effet les volcans Vulsini et Cimini continuent de fonctionner: nous en sommes sûrs par la présence simultanée de l'augite aegyrinique et de la mélanite, qui évoquent des roches sodiques telles que syénites, phonolites, trachytes. Mais nous savons que c'est au Rissien que le volcan Sabatino s'éveille, et c'est probablement à cet éveil que nous devons attribuer l'augite, la biotite et la hornblende basalitique de plusieurs couches. Il y a, en quelque sorte, double alimentation volcanique.

Mais il faut rester prudent également dans l'estimation de cette activité volcanique. On serait tenté de croire, après un examen rapide du graphique de la figure 16, que l'apport des minéraux volcaniques est allé en augmentant au cours de l'anaglaciaire. En réalité le graphique n'enregistre que des proportions, et non des quantités absolues. Que le résidu sableux vienne à diminuer, et la proportion des minéraux volcaniques augmentera, même si l'apport volcanique reste inchangé. Bref, c'est la finesse du sédiment qui fait les fortes proportions de minéraux lourds dans les couches 33, 40 et 42 . Par contre l'apport volcanique semble avoir réellement augmenté dans les couches 32 et 41, mais sans qu'on sache bien pourquoi.

Pour conclure, l'étude des minéraux lourds volcaniques nous confirme que nous sommes bien dans le Riss, puisqu'on décèle les éruptions de Bracciano, mais ne nous enseigne malheureusement rien d'autre. Inversement une étude spécialisée des couches 9 à 43 permettrait peutêtre à un volcanologue d'établir une téphrochronologie détaillée $\mathrm{du}$ volcanisme tyrrhénien à cette époque. 


\section{Corrélations chronologiques}

Les couches 9 à 43 datent donc de l'anaglaciaire rissien. Mais de quel Rissien s'agit-il? Car dans sa synthèse du Quaternaire du Latium A. C. Blanc (1957) distinguait trois phases de froid dans le Rissien: Flaminia = Pré-Riss (ou Mindel II?), Nomentana I = Riss I, Nomentana II = Riss II.

Le fil conducteur nous est fourni par l'association volcanisme-climat que l'on retrouve, identique, dans le gisement de Torre in Pietra près de Rome, au niveau de la couche 6 (BLANC 1954). Là, en effet, dans cette couche 6, on observe des pollens steppiques, des mollusques "froids", de l'Elephas antiquus et des ponces noires de Bracciano pêle-mêle dans un cailloutis de solifluxion; l'industrie de l'Abbevillien supérieur et de l'Acheuléen supérieur qu'on y trouve aussi n'ayant pas de signification puisqu'elle est remaniée. Il y a donc une ressemblance frappante avec les couches sommitales de notre remplissage lacustre de Valle Giumentina. Or cet épisode de Torre in Pietra est postérieur à la régression post-milazzienne, et antérieur à la transgression du Tyrrhénien I (= Paléotyrrhénien de Bonifay \& Mars (1959), laquelle est contemporaine du Riss II: la co u che 6 de Torre in Pietra est donc Riss I, et par voie de conséquence le sommet du lacustre C de Valle Giumentina l'est é g a lement. Cette datation est reprise dans le tableau synthétique inséré dans notre conclusion (tableau 2).

3) Les dépôts post-rissiens D

I. La discordance no. 44

Les dépôts post-rissiens $\mathrm{D}$ consistent, nous le savons, en un remplissage terreux et rougeâtre, d'épaisseur variable, prenant contact avec les dépôts antérieurs par une surface de discordance très irrégulière que nous avons numérotée 44 .

Cette discordance 44 recoupe obliquement les couches rissiennes jusque vers le niveau des couches 32 ou 33. La coupe verticale naturelle permet de l'observer avec précision: elle a un tracé en créneaux, chaque créneau ayant une forme de poche triangulaire profonde de quelques décimètres à $1 \mathrm{~m}$ environ.

La première idée qui vient à l'esprit, surtout lorsqu'on examine ces irrégularités au niveau des blocailles périglaciaires 43 , est qu'on a affaire à des festons de cryoturbation, car ce ne sont manifestement ni des poches de dissolution karstique ni des "yardangs" creusés par le vent: on songe, par exemple, aux festons cryoturbés du sommet de la couche 9 de Torre in Pietra.

Mais l'hypothèse des poches de cryoturbation ne résiste pas à un examen plus attentif. En effet les injections dûes au gel modifient la structure de détail et de la couche active et de la couche passive. Or, ici, aucun durcissement, aucune orientation des particules, ne marquent la paroi des poches: cette surface de discordance $\mathrm{tranche}$ les couches mais ne les dérange pas. Il est donc probable que l'ensemble de la ligne brisée 44 est la coupe d'un ancien versant de ravinement, chaque poche étant la section d'une rigole ("rill"). M. RADMILLI a vidé l'une de ces poches de son remplissage: elle ressemblait à un chaudron de lit torrentiel.

Pour des raisons que rien, localement, ne nous permet d'éclaircir le fond alluvial rissien de Valle Giumentina a donc été atteint par une assez violente reprise d'érosion torrentielle, forcément antérieure aux couches wêrmiennes rougeâtres. Or il est tout à fait curieux qu'une semblable reprise d'érosion soit observable en de nombreux autres points des Abruzzes orientales: j'ai cru pouvoir l'expliquer par la conjonction du climat catarissien et d'une poussée tectonique tardive (voir ici note 14), cette dernière étant par ailleurs amplement démontrée. Le phénomène a donc été régional, et non local. 


\section{Les limons éoliens no. 45}

Le remplissage terreux rougeâtre $\mathrm{D}$, discordant sur le lacustre rissien, est divisé en deux parties (No. 45 et 47) par un lit caillouteux et meuble numéroté 46 . Le tout étant couronné par le sol végétal actuel no. 48 , à peu près horizontal.

Le premier élément, la terre brun-rougeâtre no. 45, a exactement l'apparence d'un remplissage. Par sa base elle épouse fidèlement les irrégularités de la discordance 44, et elle est limitée, vers le haut par le cailloutis 46, qui s'abaisse lentement vers la rive orientale de l'alvéole lacustre. Son épaisseur est donc variable, allant de quelques décimètres à une dizaine de mètres. On ne discerne, dans sa masse, aucune stratification. Au toucher cette terre est une argile grasse, collante, mais tout de même légèrement sableuse. On y trouve aussi quelques éclats de calcaire ou de silex, mais sans disposition préférentielle. Nous n'y avons jamais trouvé aucun fossile ni aucune industrie.

La conclusion de l'étude macroscopique est donc peu douteuse: il s'agit là d'un manteau loessique ou limoneux, mis en place par voie éolienne, et qui aurait fossilisé la topographie 44; et la surface naturelle du talus serait jalonnée par le cailloutis 46.

Or tous les examens de laboratoire confirment ce premier diagnostic. La teneur en carbonates est très faible, $2 \%$ au calcimètre Bernard. Sous le microscope le $\mathrm{f} \mathrm{r} \mathrm{a} \mathrm{c} \mathrm{t} \mathrm{i} \mathrm{o} \mathrm{n}$ $\mathrm{g}$ ros s i è r e, c'est à dire supérieure à 50 microns, ne représente que $54 \%$ du sédiment. Elle est surtout faite de grains de quartz de petite taille (50 à 100 microns) et naturellement non usés. On y trouve aussi de la glauconie, de la limonite, de la magnétite, des micas, des feldspaths, et de nombreux autres minéraux. Après passage à l'acide et séparation au bromoforme on reconnaît quelques rares minéraux de la molasse et d'abondants minéraux volcaniques dont l'association laisse présumer qu'ils proviennent d'éruptions à tendance phonolithique. L a $\mathrm{fraction} \mathrm{f}$ in e comporte encore des grains de quartz, mais fort petits, et de l'argile: illite prédominante accompagnée d'un peu de kaolinite ${ }^{13}$ ). Cette argile peut provenir du fond probablement exondé de la mer Adriatique nord, puisque nous savons que nous sommes en période glaciaire.

L'analyse granulométrique de ce sédiment est très intéressante. La courbe de la figure 18, obtenue par l'emploi de tamis pour la fraction grossière et par la méthode dite de la pipette pour la fraction fine, confirme en effet qu'il y a eu triage. En voici le résumé:

$\begin{array}{lc}\text { Grandeurs caractéristiques: } & \text { Sediment } 45 \\ \text { - médiane } & 60 \text { microns } \\ \text { - premier décile } & 180 \text { microns } \\ \text { - indice d'hétérométrie14) } & 0,75\end{array}$

Loess et limons
types (CAILLEux 1953)
15 à 75 microns
35 à 180 microns
0,60 à 0,75

Par sa granulométrie le sédiment 45 se place donc vers la limite supérieure de la catégorie des loess et des limons: c'est un loess ou un limon sableux. Mais, étant donné qu'il contient très peu de $\mathrm{CaCO} 3$, il convient de l'appeler "l i m o n é ol i e n" plutôt que loess. Mais, comparée aux courbes types publiées par A. CaIlleux, notre courbe 45 présente une sérieuse anomalie. En effet, si la fraction de plus de 30 microns est très voisine de la courbe maximale des loess, la fraction inférieure s'en éloigne brusquement: si A est un stock éolien bien trié, manifestement B est un stock mal trié et d'une origine différente.

Or il existe une méthode qui permet de pousser l'analyse granulométrique plus loin, c'est la méthode des cou rbe s c a no nique s de A. Rivière (Rivière 1952a et b). Supposant les détails de construction connus, nous rappelerons simplement que si la courbe obtenue est concave vers le haut le classement a été opéré par des eaux agitées et le triage est inachevé (cas, par exemple, du sable des plages marines); mais si la courbe est

13) Examen aux rayons $X$, pratiqué par $M$. ElHAI.

14) L'indice d'hétérométrie de CaIlleux est très proche du Qdphi de Krumbein. Si l'indice est faible (par exemple 0,25 ou 0,50 ) le sédiment est bien trié. Si l'indice est fort (par exemple 4 ou 5 ) le sédiment est mal trié. 


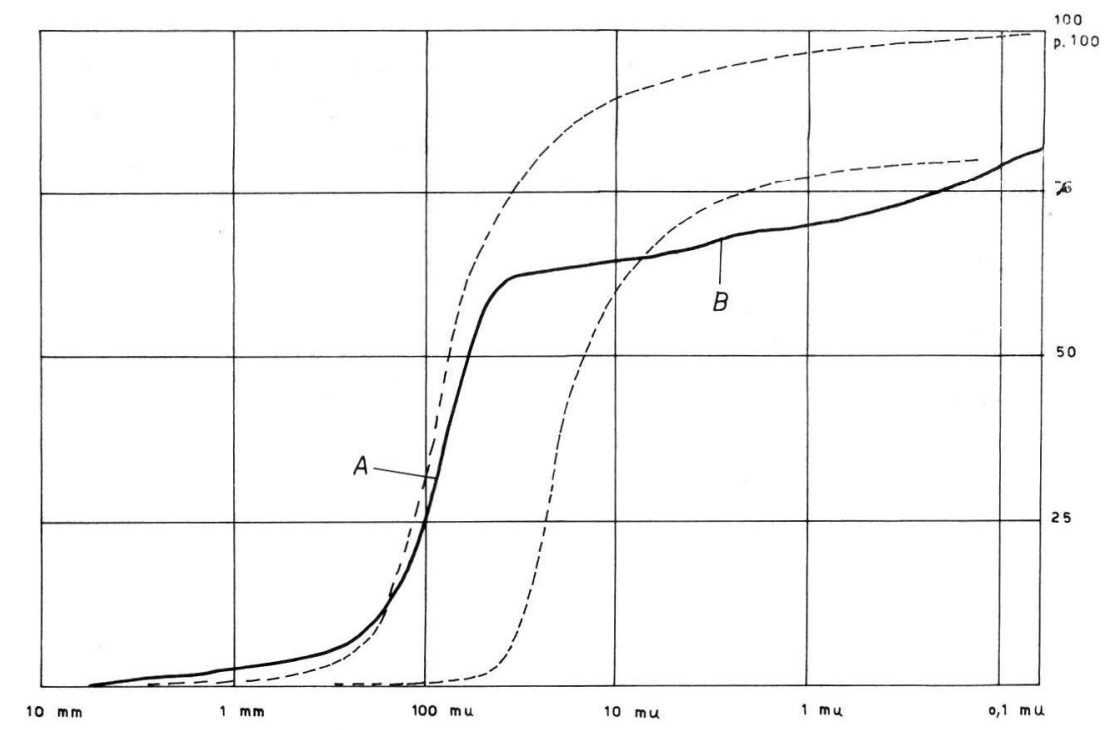

Fig. 18. Granulométrie du limon 45. En tireté, pour comparaison, courbes extrêmes des loess et limons éoliens, d'après CaIlleux (1953): loess sableux à gauche, lehm fin à droite. La courbe du sédiment 45 (trait plein) révèle l'existence d'un stock purement éolien (A) et d'un stock plus fin (B) non éolien. Le raccord se fait vers 30 microns.

concave vers le bas le classement résulte d'une décantation parfaite en eaux calmes (cas, par exemple, d'argiles kaoliniques).

Appliquée à notre sédiment 45 la méthode du Prof. Rivière confirme absolument que la portion A est d'origine éolienne: la courbe de cette portion A est même presque superposable à la courbe canonique d'un échantillon d'authentique limon éol'en ident fié en Vendée par Mme Ters et contemporain du loess récent würmien (fig. 19). Mais elle confirme aussi que le stock B est d'origine complexe: alors que Mme Ters a pu démontrer que la courbe canonique de la partie fine des limons éoliens est concave vers le haut (Ters 1961), notre portion B est légèrement concave vers le bas, ce qui dénote l'intervention d'une décantation.

Par conséquent notre limon 45 a bien été mis en place par le vent, mais ou bien il a été légèrement remanié sur place par ruissellement, ou bien il a conservé la granulométrie de deux argiles initiales différentes: mais nous n'avons aucun argument pour choisir entre ces deux variantes.

Reste à savoir sous quel climat ce limon a été déposée. Certes, il existe des limons éoliens de climat chaud, mais ils sont plus jaunâtres que rougeâtres. D'autre part on ne s'expliquerait pas, en climat chaud et sec, le présence épisodique dans notre dépôt de graviers petits mais très aigus. Par contre un climat désertique froid permet d'invoquer la glissade des débris gélifractés sur sol gelé, et il s'accorde mieux avec le contexte local: le limon 45 a certainement été mis en place en climat froid e t s e c.

III. L es couches su périeures

Ainsi qu'il a été dit la couche 46 marque très vraisemblablement la surface du talus des limons éoliens 45, surface doucement inclinée vers l'Est. C'est une couche caillouteuse non cimentée, un lit discontinu de pierraille qui peut atteindre jusqu'à $50 \mathrm{~cm}$ d'épaisseur. L'interprétation en est très délicate. 


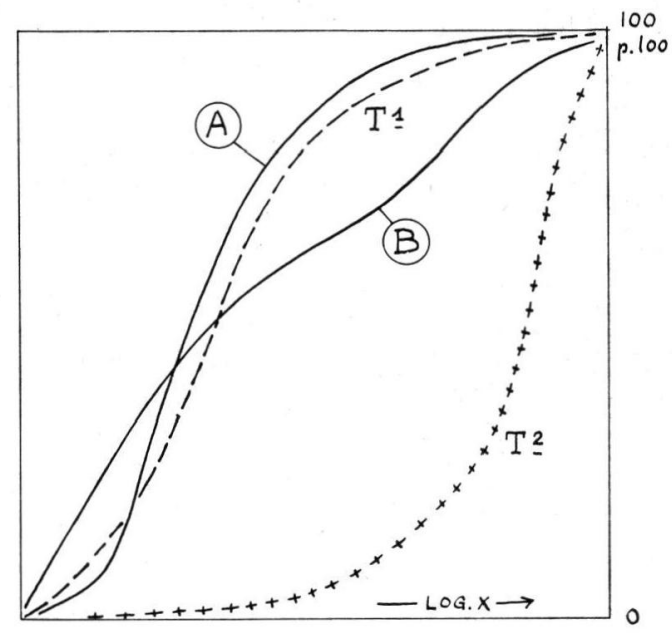

Fig. 19. Courbes canoniques du limon 45. La partie A et la partie B de la courbe de la figure précédente ont été reportées dans un carré selon la méthode Rivière (1952 a et b). Pour comparaison on y a également reporté les courbes caractéristique d'un authentique limon éolien de Vendée (échantillon no. 11 de Mme Ters $(1961$, p. 495 et 496): fraction T 1 supérieure à 100 microns, fraction T 2 inférieure à 32 microns. Bien que les limites dimensionnelles ne soient pas rigoureusement identiques, la comparaison est intéressante: on voit bien que $\mathrm{A}$ ressemble à $\mathrm{T} 1 \mathrm{~m}$ mais que $\mathrm{B}$ ne ressemble aucunement à $\mathrm{T} 2$. Donc $\mathrm{A}$ est bien éolien, tandis que $\mathrm{B}$ a une origine plus complexe.

Le premier problème est celui de la mise en place du matériel. Dans ce dépôt on trouve pêle-mêle des cailloux calcaires à angles vifs (diamètre: 2 à $15 \mathrm{~cm}$ ), des fragments de cuirasse ferrugineuse et de calcaire meuliérisé (diamètre: 5 à $25 \mathrm{~cm}$ ) dont les angles sont très légèrement émoussés, et une grande abondance de silex: rognons de silex bruts, éclats de silex naturels, silex taillés du Paléolithique inferieur patinés et évidemment remaniés, silex taillés Levalloiso-Moustériens apparemment frais. La matrice ressemble au limon 45, mais enrichie de granules meubles de limonite et de manganèse. Aucune stratification, aucun émoussé notable, rien qui dénote l'intervention du ruissellement. On ne voit pas par quel processus autre que la solifluxion nivale ce matériel hétérogène et hétérométrique aurait pu être mis en place à la surface du dépôt 45: le cli m a t ét a i t $\mathrm{froid}$, et à tendance humide, par conséquent. Mais il admettait des vents actifs, puisqu'on trouve dans la matrice limoneuse des minéraux lourds de la molasse en quantité non négligeable.

Bref, par rapport au climat de la couche 45 , il y a une évolution sensible mais pas de différence radicale: nous sommes toujours en climat périglaciaire.

Pareille observation vaut d'ailleurs pour les couches 47 et 48 . La couch e 47 est faite d'une terre argileuse tout à fait comparable, comme texture, à la couche 45 , mais de couleur moins rougeâtre mais plus brunâtre. Je ne l'ai pas étudiée en détail en particulier parcequ'elle ne recèle aucune industrie et, surtout, qu'elle paraît prolonger l'épisode des limons éoliens 45 : en certains endroits en effet le cailloutis 46 n'existe pas et le sédiment 47 se raccorde insensiblement au sédiment 45 . On a l'impression, sur le terrain, que le colmatage du versant par sédimentation éolienne en climat sec a tout simplement repris après l'intermède humide no. 46.

La couche 48 , épaisse d'une cinquantaine de centimètres, est la dernière de la série, c'est elle qui est immédiatement surmontée par la terre végétale actuelle. Elle a à peu près le même aspect que les limons antérieurs, sauf qu'elle est nettement brune et 
qu'elle contient quelques cailloux bruts et quelques silex taillés. Etant remaniée par la charrue, car le bassin de Valle Giumentina est régulièrement mis en culture, cette couche est d'une interprétation douteuse. Les fragments rocheux ont évidemment été apportés soit par solifluxion soit par un bref ruissellement: en tous cas ils ont pris la forme contournée et la surface rugueuse des cailloux de rendzine. La couleur brune provient probablement d'un début d'évolution pédologique. Bref cette couche ultime pourrait bien n'être que la partie supérieure des limons éoliens remaniés d'abord par solifluxion ou ruissellement, ensuite par les processus pédogénétiques, enfin par l'homme lui-même. L'âge du premier remaniement nous est donné par les silex taillés et qui accompagnent ces cailloux, et qui sont du Paléolithique supérieur de faciès abruzzais, appelé "bertonien" par M. Radmilli. Le Bertonien étant, dans le bassin abruzzais du Fucino scellé par des grèzes litées de la dernière pulsation würmienne (fin Würm III ou hypothétique Würm IV), on voit combien cette couche 48 est récente.

\section{Les corrélations w ürmiennes}

Nous avons réservé pour la fin le problème de la datation des couches 45 à 48 , car ces couches présentent une remarquable unité sédimentologique: de la base de 45 au sommet de 48 on est dans le même remplissage périglaciaire avec tantôt des preuves de poussée aride tantôt des preuves de poussée humide; toute datation de l'une des parties peut donc servir de point de repère pour dater l'ensemble.

Or par ailleurs ces couches ne sauraient être très anciennes. Elles se trouvent à fleur de sol, à l'air libre, dans une topographie en creux où le moindre sédiment continental est comme pris au piège. De plus nous disposons de terminus relativement fermes. Le terminus a nte quem est la grande reprise d'érosion fini-rissienne, le terminus post quem est l'industrie bertonienne du Würmien expirant. Quelle importante période froide autre que le W ü $\mathrm{rm}$ i e n pourrait faire l'affaire? Notons au passage que la nature plutôt phonolithique des l'association de minéraux lourds volcaniques de la couche 45 consolide cette appréciation, puisque au Würmien, les Colli Laziali, Rocca Monfina et les Campi Flegrei étaient entrés en éruption: or il s'agit de volcans plutôt basiques. Reste à savoir s'il est possible d'atteindre à plus de précision à l'intérieur du Würm.

Pour ce qui est des limons éoliens 45 , il est infiniment probable qu'ils appartiennent à la série des dépôts éoliens rougeâtres épars tout au long du littoral italien, et datés du Würm II: dunes rougeâtres de Castiglioncello en Toscane, dunes rougeâtres du Cap Palinuro au Sud de la Campanie, remplissage éolien rougeâtre G de la grotte Romanelli dans les Pouilles (Blanc 1942), etc. Cette série italienne appartient elle-même, à ce qu'il semble, à la grande famille des limons rouges de la Méditerranée: seconde nappe brune de Corse (Ottmann), limons rouges I de Cyrénaïque (Demangeot 1956), limons atériens d'Afrique du Nord (Balout 1955), limons auquels j'apparenterais volontiers les brèches "mortadelle" qui plongent sous la mer aux environs de Monaco ou d'Athènes.

Il n'y a pas de raisons pour que les conditions de froid et d'aridité qui caractérisent la Méditerranée au Würm II (Tongrorgi 1950, Guillien 1962) n'aient pas contaminé également les Abruzzes: au contraire leur position plus interne dans l'Apennin, et l'exondation partielle de l'Adriatique ont dû faire là le climat du Würm II encore plus continental. La meilleure preuve est que les glaciers de l'Apennin central descendaient moins bas qu'au Würm I alors qu'il faisait manifestement plus froid (EMILIANI 1955).

\section{Conclusion}

Le tableau suivant résume les conclusions certaines ou conjecturales auquelles nous sommes progressivement parvenus. 
T a ble a u 2

\begin{tabular}{|c|c|c|c|}
\hline $\begin{array}{l}\text { A } 1 \text { p e s } \\
\text { Würm III } \\
\text { Würm II }\end{array}$ & $\begin{array}{l}\quad \text { L a t i u m } \\
\text { Pontinia III } \\
\text { Pontinia II }\end{array}$ & $\begin{array}{l}\text { V. G i u m e n t in a } \\
\text { couche } 48 \\
\left\{\begin{array}{l}\text { couches } 45 \text { et } 46 \\
\text { (et } 47 \text { ?) }\end{array}\right.\end{array}$ & \multirow{7}{*}{$\begin{array}{l}\text { érosion généralisée dans les } \\
\text { Abruzzes } \\
\text { (couche } 6 \text { de Torre in Pietra) } \\
\text { transgression paléotyrrhénienne } \\
\text { régression post Milazzienne }\end{array}$} \\
\hline Würm I & Pontinia I & \multirow{3}{*}{ (lacune 44) } & \\
\hline & & & \\
\hline Riss II & Nomentana II & & \\
\hline Riss I & Nomentana I & couches 9 à 43 & \\
\hline & & \multirow{2}{*}{||||} & \\
\hline Pré-Riss ? & Flaminia & & \\
\hline ferretto & ? & cuirasse no. 8 & $\begin{array}{l}\text { transgression d'Urbino (Corse) } \\
\text { nappe rouge des vallées } \\
\text { actuelles (Corse) }\end{array}$ \\
\hline \multirow[t]{2}{*}{ Mindel I et II } & Cassia ? & brèche 4 à 7 & \\
\hline & & poudingue 3 & \\
\hline Günz & ? & $\begin{array}{l}\text { couche } 2 \\
\text { couche } 1\end{array}$ & mégabrèches d'Aquila? \\
\hline
\end{tabular}

Beaucoup d'incertitudes subsistent. Antérieurement au Mindélien la datation est purement conjecturale. Nous ne savons pas non plus, s'il y a eu un ou plusieurs Mindéliens, ni ce qui s'est passé exactement dans l'inter-Mindel-Riss, ni au cours de la lacune 44, etc. Inversement nous sommes sûrs que des ferretisations et des rubéfactions ont eu lieu, ici comme dans la plaine du Pô, avant le Rissien. Et nous discernons les modulations du froid rissien et du froid würmien avec une certaine précision et leur incidence sur l'occupation du sol par les hommes préhistoriques.

Bref, Valle Giumentina compte certainement parmi les plus beau gisements de Paléolithique à ciel ouvert de toute l'Italie.

Addendum. Cette étude était terminée depuis longtemps lorsque le Prof. Radmilli écrivit ses conclusions sur le gisement des Svolte de Popoli. Bien que je ne connaisse pas personellement ce gisement il me paraît impossible d'admettre, du moins en l'état de nos connaissances, les bouleversements que mon collègue et ami introduit dans la chronologie de Valle Giumentina.

Le pivot de ma démonstration étant l'âge rissien du remplissage $C$ de Valle Giumentina, il me paraît inacceptable, du point de vue sédimentologique, que la couche 47 de Valle Giumentina, modeste et quasi superficielle, puisse correspondre à elle-seule non seulement à tout le Würm II et I, mais encore à tout l'inter Riss-Würm et à toute la moitié supérieure du Riss. L'argumentation de M. Radmilli repose, elle, sur l'absence de patine des instruments levalloiso-moustériens de la couche no. 46, et sur l'âge nécesairement pré-Würm du Levalloiso-moustérien. Faute de compétence j'accepterai sans discuter cette dernière proposition, mais le premier point, lui, ne me paraît nullement démontré. L'interprétation des patines doit être menée avec le maximum de prudence. D'une part il est bien normal que les instruments du Paléolithique inférieur soient nettement plus patinés que ceux du Levalloiso-moustérien. D'autre part rien ne s'oppose à ce que les silex levalloiso-moustériens aient séjourné dans le sol plusieurs dizaines de millénaires sans avoir été altérés, ni à ce qu'ils aient ensuite été délogés par la solifluxion et déplacés de 100 ou $200 \mathrm{~m}$ sans subir de polissage appréciable: les stries de solifluxion, d'ailleurs, ne prennent bien que sur du matériel préalablement patiné. Bref, pour moi Levalloiso-moustérien de la couche 46 n'est pas en place et, de ce fait, le contexte sédimentologique gardant tout sa valeur, la couche 46 est würmienne. 


\section{Bibliographie}

Bally, A.: Untersuchungen in den SE-Abruzzen. Zürich 1954.

Balout, L.: Préhistoire de l'Afrique du Nord. Paris, Arts et métiers graphiques, 544 p., 1955.

Blanc, A. C.: Variazioni climatiche ed oscillazioni della linea di riva del Mediterraneo centrale durante l'era glaciale. Geol. Meere u. Binnengewässer, 5, 2, 137-219, 1942. - - Giacimento ad industria del paleolitico inferiore (Abbevilliano superiore-Acheuleano) e fauna fossile ad Elephas a Torre in Pietra presso Roma. Riv. Antrop., 41, 1954. - - On the Pleistocene sequence of Rome Paleoecologic and archeologic correlations. Quaternaria, 4, 95-109, 1957. - - Torre in Pietra, Saccopastore e Monte Circeo. La cronologia dei giacimenti e la paleogeografia quaternatria del Lazio. Bull. Soc. Geog. Ital. 1958.

Blanc, A. C.; Lona, F. et SETtepassi, F.: Ricerche sul Quaternario glaziale. 1- Una torba ad Abies, malacofauna montana e criosedimenti nel Pleistocene inferiore di Roma. Il periodo glaciale Cassio. Quaternaria, 2, 151-158, 1955.

Blanc, A. C.; Tongiongi, E. et Trevisan, L.: Le Pliocène et le Quaternaire aux alentours de Rome. IVème Congrès Inqua, Roma-Pisa 1953.

Bonifay, E. et Mars, P.: Le Tyrrhénien dans le cadre de la chronologie quaternaire de la Méditerranée. Bull. Soc. Géol. Fr. 51, 62-78, 1959.

Bourdier, F.: Le bassin du Rhône au Quaternaire. Géologie et Préhistoire, Paris, CNRS, 2 volumes, 1961.

CaIlleux, A: Les actions éoliennes périglaciaires en Europe. Mém. Soc. Géol. Fr., 21, no. 46, 1942. - - Le loess et les limons éoliens de France. Bull. Serv. Carte Géol. Fr., 51, no. 240, 1-24, 1953.

Cailleux, A. et Tricart, J.: Initiation à l'étude des sables et des galets. Paris, CDU, 3 vol., 1959.

Chiarugi, A.: Le epoche glaciali dal punto di vista botanico. Acc. Naz. Lincei, 55-109, 1950.

Comer, A.: Elementi di Pedologia climatica, Udine. Istituto delle Edizioni Accademiche, 193 p., 1937.

Demangeot, J.: L'évolution quaternaire des côtes de Cyrénaïque. Bull. Soc. Geogr. Egypte, 33-42, 1956. - - L’Inter Mindel-Riss en Italie centrale. Bull. Soc. Géol. Fr., 597-602, 1963. - Géomorphologie des Abruzzes adriatiques. Thèse de Doctorat d'Etat. Paris, Mémoires et Documents, CNRS, 1965.

Demangeot, J. et Radmilli, A. M.: Les gisement quaternaire de la Valle Giumentina (Abruzzes adriatiques), Stratigraphie et Palethnologie. Contributi di Scienze geologiche, suppl. à la Ricerca Scientifica, 3, 11-123, 1953. - - Sur la découverte de Paléolithique inférieur dans un gisement lacustre des Abruzzes. Actes du Vème Congrès International du Quaternaire, 607-698, Rome-Pise, 1953.

Demangeot, J. et Ters, M.: Application de la méthode des minéraux lourds à quelques problèmes morphologiques des Abruzzes adriatiques. Bull. Soc. Géol. Fr., 264-272, 1962.

Emiliani, C.: Pleistocene temperature variations in the Mediterranean. Quaternaria, 2, 87-98, 1955.

FranchI, S.: Sul grande sviluppo dei ghiacciai pleistocenici della Majella. R. C. R. Acc. Lincei, Sc. Fis. Mit. Nat., 28, 139-143, 1919.

FRÄNZLE, O.: Untersuchungen über Ablagerungen und Böden im eiszeitlichen Gletschergebiet NordItaliens. Erdkunde, 13, 289-297, 1959.

Gabert, P.: Les plaines occidentales du Pô et leur piedmonts, étude morphologique. Gap, 531 p., 1962.

Guillien, Y.: Néoglaciaire et Tardiglaciaire: géochimie, palynologie, préhistoire. Ann. Géogr. no. 383, 1-35, 1962.

Leopardi, G.; Pannuti S. et Radmilli A. M.: Esplorazioni paletnologiche in Abruzzo, anno 1956. Bull. Paletnol. Ital., 66, 1957.

Leopardi, G. et Radmilli, A. M.: Esplorazioni paletnologiche in Abruzzo, anno 1955. Bull. Paletn. Ital., 65, 11p., 1956.

LožEK, V.: Quaternary travertines of Czechoslovakia. Vème congrès INQUA, Résumés 110-111, Madrid 1957.

Maignien, R.: Le cuirassement des sols en Guinée, Afrique Occidentale. Mém. Service Carte Géol. Alsace-Lorraine, no. 16, 239 p., 1958.

Olivierr, R.: Le argille halloysitiche dei depositi lacustri nella Valle Giumentina (Laghi morti della Majella). Acc. Naz. Sc. Lett. Arti, Modena, 6, 3, 44-59, 1961.

Ottmann, F.: Les formations pliocènes et quaternaires sur le littoral corse. Mém. Soc. Géol. Fr., nouv. Série, 37, 4, 176 p., 1956.

Paganelit, A.: Analisi pollinica del deposito pelistocenico di Gelagna Bassa (Appennino umbromarchigiano). Boll. Serv. Geol. Ital. 81, 257-278, 1959. 
Radmilli, A. M.: Una nuova facies del Paleolitico superiore italiano presente in Abruzzo. Boll. Paletn. Ital., 73-105. - - Attività della Sopraintendenza alle Antichità di Chieti e della Sezione abruzzese-molisana dell'Istituto Italiano di Paleontologia umana. Bull. Paletnol. Ital., 8, 1953. - - Abruzzo preistorico - Il Paleolitico inferiore-medio abruzzese. Sansoni, 1964.

Rivière, A.: Expression analytique générale de la granulométrie des sédiments meubles, indices caractéristiques et interprétation géologique, notion de faciès granulométrique. Bull. Soc. Géol. Fr., 155-167, 1952. - - Sur la représentation graphique de la granulométrie des sédiments meubles, interprétation des courbes et application. Bull. Soc. Géol. Fr. 145$154,1952$.

Rosa, C: in Balzano: Studi di preistoria e storia nella Valle della Vibrata. Teramo, 1909.

Ters, M.: La Vendée littorale, étude de géomorphologie. Paris, Institut de Géographie, 578 p., 1961.

Tongrorgr, E.: Le epoche glaciali dal punto di vista paleoclimatologico, in: Le epoche glaciali, problemi attuali di Scienza e di Cultura, 16. Acc. Naz. Lincei, 120-137, 1950.

Woldstedt, P.: Das Eiszeitalter, Grundlinien einer Geologie des Quartärs. Stuttgart, F. Enke, 2 vol., 1958.

Manuskr. eingeg. 29. 3. 1966.

Anschrift der Verf.: Prof. J. Demangeot, 4 rue Albert Lautman, 31-Toulouse (France);

Prof. A. M. Radmilli, Istituto di Paleontologia Umana dell’Universita. Pise, Via S. Maria, 31 (Italie). 